\title{
LE ALLEANZE ELETTORALI. IDENTITÀ PARTITICHE E LOGICHE COALIZIONALI
}

\author{
di Aldo Di Virgilio
}

\section{La politica delle alleanze nella transizione italiana}

L'emergere di una competizione tra coalizioni partitiche rappresenta una delle principali conseguenze delle regole per l'elezione dei due rami del parlamento, dei consigli regionali e degli organismi amministrativi di comuni e province adottate in Italia fra il 1993 e il $1995^{1}$. Nell'operatività dei nuovi sistemi elettorali, la scelta dell'aggregazione fa capo agli aspetti maggioritari del meccanismo di voto (l'elezione dei deputati e dei senatori nei collegi uninominali, l'attribuzione del premio di maggioranza nei consigli regionali, l'elezione del sindaco e del presidente della provincia), ancorati, con maggiore o minore forza cogente, allo scopo di «votare per eleggere un governo» ${ }^{2}$. In tal modo, la politica delle alleanze si è affermata come un elemento permanente del processo elettorale, decisivo ai fini del risultato e non privo di implicazioni sull'evoluzione strutturale del sistema partitico. La formazione delle coalizioni e la progressiva ridefinizione dell'offerta coalizionale, in effetti, hanno cadenzato fin qui i passaggi elettorali della transizione italiana. La forza aggregativa del Pds e la sua capacità di attivare una logica di schieramento si rivelarono determinanti, in assenza di coalizioni alternative, per il successo della sinistra negli importanti test elettorali locali dell'estate e dell'autunno 1993. La formula inventata da Silvio Berlusconi per colmare il deficit di offerta sul

1 Si tratta delle norme contenute nelle leggi n. 276 (Senato) e n. 277 (Camera) del 4 agosto 1993, nella legge n. 43 del 23 febbraio 1995 (regioni) e nella legge n. 81 del 25 marzo 1993 (province e comuni).

2 Non senza esiti paradossali, se si pensa ad esempio che un sistema con 1'80\% di seggi proporzionali come il nuovo sistema elettorale regionale è, a questo scopo, «più maggioritario» di un sistema con il $75 \%$ dei seggi maggioritari come quello parlamentare (D'Alimonte 1995, 531).

RIVISTA ITALIANA DÍ SCIENZA POLITICA / a. XXVI, n. 3, dicembre 1996 
fronte moderato - il cartello elettorale a geografia variabile che vedeva la sua nuova formazione politica alleata al Nord con la Lega e al Sud con il Msi-An - consentì alle destre di vincere le elezioni politiche del marzo 1994. Nella fase successiva, il vincolo delle alleanze ha determinato la rottura del polo di centro e il riequilibrio coalizionale che ne è scaturito ha favorito, alle elezioni regionali dell'aprile $1995^{3}$, il dispiegarsi di una competizione tendenzialmente bipolare tra due schieramenti di analoga forza.

La dinamica coalizionale non sembra ancora aver raggiunto, ciò nonostante, un punto di equilibrio stabile. Le aggregazioni elettorali del 1994 si sono dimostrate fragili e poco coese, paralizzate da modalità di regolazione interna a carattere prevalentemente spartitorio, incapaci di sviluppare un'identità propria distinta e sovraordinata rispetto all'identità delle loro singole componenti partitiche. La prova del governo Berlusconi e la defezione della Lega dal Polo per le libertà, d'altro canto, hanno dimostrato che confezionare un'alleanza elettorale vincente è cosa ben diversa dal creare una stabile maggioranza di governo. L'instabilità delle coalizioni elettorali deve molto all'ancor troppo limitata esperienza delle nuove regole e al retaggio culturale degli attori. Su di essa pesa, inoltre, l'elevato numero di partiti e movimenti che ha preso parte fin qui al gioco coalizionale, rendendone più difficile la conduzione. Si deve tenere presente infine, e soprattutto, che la scelta dell'aggregazione non costituisce la sola decisione strategica alla quale gli attori sono sollecitati a dare risposta.

Nei nuovi sistemi elettorali - che proprio per questo si caratterizzano come sistemi misti - la competizione tra coalizioni, basata sulla solidarietà di schieramento e sulla rivalità tra blocchi antagonisti, si combina infatti, in forme distinte, con l'attribuzione proporzionale di una certa quota di seggi. La logica della competizione coalizionale si trova in tal modo intrecciata, con diverse modalità, con la tradizionale competizione su base partitica, basata su un criterio di distinguibilità individuale che esalta la rivalità tra alleati di schieramento collocati «gomito a gomito» nello spazio politico ${ }^{4}$. Questa coesistenza di logiche

3 Sul punto si vedano D'Alimonte (1995) e Di Virgilio (1996).

4 Occorre considerare, in proposito, che la nuova legge elettorale per la Camera prevede una distribuzione dei seggi proporzionali su base nazionale mediante l'applicazione del quoziente naturale e induce quindi, per questa via, un effetto riduttivo assai 
competitive diverse e per certi versi in conflitto tra loro ${ }^{5}$ interferisce con la politica delle alleanze elettorali da più punti di vista: ribadisce la distintività dell'attore-partito rispetto all'attorecoalizione; misura il peso specifico dei partiti all'interno della coalizione in quanto - nel caso del sistema elettorale per la $\mathrm{Ca}$ mera e del sistema elettorale regionale - chiede all'elettore di esprimere oltre al voto maggioritario (eventualmente strategico) un voto proporzionale (presumibilmente sincero); alimenta in tal modo quel fenomeno di «proporzionalizzazione del maggioritario» rilevato nel 1994. Così stando le cose, l'interdipendenza tra maggioritario e proporzionale diventa un ingrediente non secondario della politica delle alleanze: rappresenta per le coalizioni un fattore endogeno di precarietà, in quanto definisce una struttura di incentivi entro cui gli interessi dell'attore-partito non sempre coincidono con quelli della propria coalizione, e sembra costituire, in definitiva, una condizione sufficiente a procrastinare l'uscita del sistema partitico dalle secche di una sorta di «transizione permanente».

Cosa hanno aggiunto a questo quadro le elezioni del 21 aprile 1996? Come si è caratterizzata la competizione sul terreno della politica delle alleanze? $\mathrm{E}$, più specificamente, qual è stata la configurazione dell'offerta coalizionale? E quale il «raccordo» tra maggioritario e proporzionale? Cosa si ricava, infine, dal confronto con le elezioni politiche del 1994? Nel rispondere a tali domande, questo lavoro prende in esame la composizione delle coalizioni elettorali e le modalità di regolazione prevalenti al loro interno. L'aspettativa, da un lato, è che gli attori (partiti e coalizioni) abbiano acquisito maggiore «familiarità» con le nuove regole e maturato, a riguardo, un autonomo processo di apprendimento e, dall'altro, che il sistema elettorale, giunto alla sua seconda prova, esibisca con maggiore evidenza la qualità

limitato. L'unico vincolo in tal senso è costituito dalla soglia del $4 \%$ (su scala nazionale) fissata per l'accesso alla ripartizione dei seggi proporzionali della Camera. Si tratta tuttavia di un vincolo che opera in senso riduttivo soltanto in circostanze particolari, ad esempio, come è avvenuto nel 1994, quando un'elevata frammentazione partitica si accompagna alla distorta percezione che gli attori hanno della propria consistenza elettorale e alla loro assoluta inesperienza delle nuove regole di voto. Nel 1996, non a caso, la clausola del $4 \%$ ha tagliato fuori, senza troppa sorpresa, soltanto Verdi, Lista PannellaSgarbi e Movimento sociale-Fiamma tricolore, mentre le liste in grado di ottenere una propria rappresentanza in quota proporzionale sono passate da sei a sette.

5 Un esame di questi elementi di conflitto è contenuto in D'Alimonte e Chiaramonte (1995) e in Katz (1996) per la legge elettorale parlamentare, e in D'Alimonte (1995) per la legge elettorale regionale. 
dei suoi vincoli e dei suoi incentivi, per come essi emergono dalle concrete scelte degli attori in questione. Se ne dovrebbero poter ricavare utili indicazioni sull'effettiva rilevanza assunta dal fattore «politica'delle alleanze» in molti aspetti del processo elettorale.

\section{Dal 27 marzo al 21 aprile: la ridefinizione degli schieramenti}

Il 21 aprile 1996 il quadro delle alleanze elettorali per la competizione maggioritaria si presentava assai diverso rispetto alle elezioni di due anni prima: da quattro che erano (Progressisti a sinistra, Patto per l'Italia al centro, Polo per le libertà e Polo del buongoverno a destra) le aggregazioni si erano ridotte a due, centro-destra e centro-sinistra. Tale passaggio, per un verso, costituiva il punto di arrivo di una serie di eventi che correva lungo l'intero arco della XII legislatura (il travaglio post-elettorale delle due coalizioni sconfitte dal verdetto delle urne e la ridefinizione della strategia e delle scelte tattiche delle loro principali componenti partitiche - Pds e Ppi, rispettivamente -; la rottura della coalizione vincente; il definitivo logoramento degli equilibri coalizionali di partenza nel corso dei quindici mesi trascorsi da Lamberto Dini a Palazzo Chigi alla testa di un governo quasi-tecnico). Per altro verso, rappresentava invece il risultato della frenetica attività negoziale che, nelle cinque settimane comprese tra il decreto presidenziale di scioglimento anticipato del Parlamento (15 febbraio) e il termine ultimo per il deposito delle candidature (20 marzo), aveva plasmato le due nuove alleanze, fissandone i confini e la configurazione e definendo in concreto i termini tecnico-politici degli accordi.

La dicotomizzazione del panorama coalizionale ha comportato un complesso rimescolamento di posizioni e numerose novità sul piano delle modalità di coalition building. In prima approssimazione, come si nota nella tabella 1 , merita osservare anzitutto che il passaggio dalle quattro aggregazioni del 1994 ai due blocchi elettorali del 1996 ha modificato profondamente i precedenti equilibri coalizionali, con andamento e conseguenze asimmetrici. Sul versante di centro-destra, lo sfaldamento della precedente compagine coalizionale determina, infatti, un «dimagrimento» del formato dell'alleanza elettorale, cui si accompagna una frammentazione dell'area e il proporsi di competitori 
«interni» (elementi, questi ultimi, quasi sempre esiziali in un'elezione maggioritaria). Nell'area di centro-sinistra, al contrario, viene a formarsi un'aggregazione nuova e assai estesa, i cui confini, da un lato, coincidono con quelli del cartello progressista del 1994 e, dall'altro, fanno incursione nel territorio controllato nel 1994 dal Polo per le libertà. È importante anticipare, in secondo luogo, che questo riequilibrio tra gli schieramenti si associa, sul piano della tecnica coalizionale, a un diverso grado di continuità/innovazione. Nel caso del centro-destra, l'accordo segue la falsariga di due anni prima, con alcuni importanti scostamenti dettati dalla diversa configurazione dell'aggregazione e dalla disponibilità, in questa occasione, di dati recenti e attendibili sui rapporti di forza elettorali prevalenti all'interno della coalizione. Nel caso del centro-sinistra, invece, l'operatività dell'accordo esibisce, rispetto al 1994, un significativo grado di innovazione, che rispecchia un investimento strategico sulle molteplici (e non sempre lineari) opportunità incorporate nel meccanismo di voto e, di conseguenza, l'adattamento degli attori ai vincoli del nuovo sistema elettorale.

L'alleanza di centro-destra ha trovato dunque una ridefinizione per sottrazione che, da più punti di vista e in concomitanza con gli sviluppi che si registrano sul fronte opposto, la rende, rispetto al 1994, più debole e vulnerabile. I fattori che concorrono a questo esito sono essenzialmente tre: $(a)$ il profilarsi di un'agguerrita concorrenza all'interno della propria area di riferimento elettorale; $(b)$ lo spostamento verso destra del baricentro della coalizione e, conseguentemente, la minore capacità di presidiare il fianco sinistro della coalizione e di «parlare» quindi all'elettorato intermedio, collocato tra i due schieramenti; (c) la diminuita coesione della coalizione che si manifesta, con apparente paradosso, malgrado essa veda ridursi il proprio perimetro.

Nel passaggio 1994-1996, come si può osservare nella tabella 1, l'aggregazione di centro-destra perde una sua componente basilare pur se in apparente declino (la Lega), una scheggia partitica ritenuta trascurabile (il Movimento sociale-Fiamma tricolore, che si distacca da Alleanza nazionale dopo il congresso di Fiuggi del febbraio 1995), la presenza organica di un irrequieto

\footnotetext{
6 Sull'appartenenza di una larga maggionanzadle de favore del centro-destra - compresi i đue terzi dell elettorato leghista - a una mesima area moderata, si veda Calvi e Vannucci $(1995,41)$.
} 
TAB. 1. L'evoluzione dell'offerta coalizionale

Elezioni politiche 1994

Elezioni politiche 1996

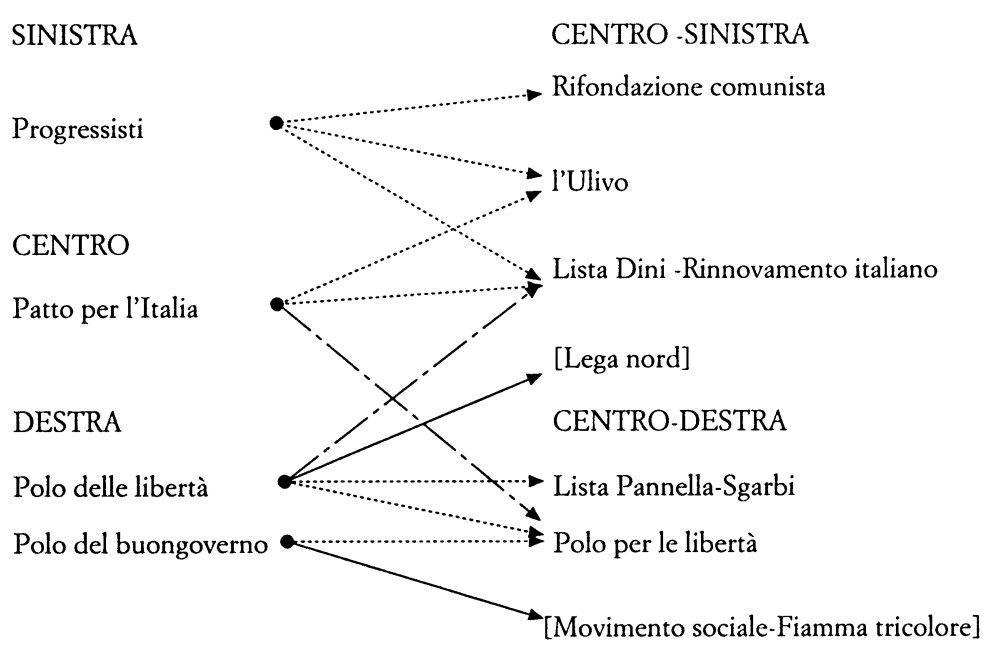

spostamenti infracoalizionali

$\longrightarrow \ldots$ spostamenti intercoalizionali

exit dal gioco coalizionale

socio minore (i riformatori di Pannella). Si tratta di pezzi coalizionali di diseguale calibro e rilevanza, ciascuno dei quali, decidendo di «correre da solo» nei collegi uninominali, insidia tuttavia le possibilità di successo dei candidati del Polo per le libertà ${ }^{7}$. Se l'autonoma presenza del Msft nella competizione

7 Più specificamente, nei collegi uninominali della Camera, i candidati del Polo si sono trovati a fronteggiare in 195 casi un candidato leghista, in 34 casi un candidato leghista e un candidato missino, in 145 casi un candidato missino. In 79 collegi il candidato del Polo non aveva avversari «interni» (se si escludono dal novero i candidati della Lista Pannella-Sgarbi, formazione con la quale il Polo conclude un'intesa politico-elettorale a una settimana dal voto). Di tali candidature, soltanto le candidature leghiste erano competitive e ciò ha reso tripolare l'offerta elettorale nei collegi del Nord. Alle due coalizioni, infatti, in tali collegi si affiancava un terzo polo, la cui concentrazione territoriale lo poneva in condizione di sfidare anche «in uscita» - ovvero in sede di rappresentanza parlamentare - la strutturazione bipolare raggiunta sul piano coalizionale (ciò che lo rendeva qualitativamente distinto dal terzo polo centrista del 1994). Prima di decidersi per lo «splendido isolamento», la Lega era rimasta a lungo «sul mercato», 
maggioritaria determina, a conti fatti, un costo politico superiore ad ogni previsione della vigilia ${ }^{8}$, è stato tuttavia il divorzio dalla Lega ad incidere con maggiore evidenza sul carattere della coalizione. L'assenza del Carroccio ha infatti privato il Polo dei suoi tratti più peculiari - in particolare l'assetto a geografia variabile connesso all'articolazione dello schieramento in due aggregazioni macroregionali, «nazionalizzate» dalla presenza in entrambe di Forza Italia (assetto decisivo per il successo elettorale del 27 marzo come, peraltro, per il fallimento della successiva prova di governo) - e ha meridionalizzato il profilo della coalizione ( $e$, in prospettiva, della sua espressione parlamentare), riducendone il richiamo presso ampie fasce di elettorato moderato del Nord.

Com'era accaduto nelle elezioni regionali del 1995, la presenza della Lega viene surrogata da Alleanza nazionale, che estende così ai collegi del Nord e della Zona rossa la sua rilevanza coalizionale, a completamento della strategia di legittimazione percorsa dal partito di Fini nell'ultimo biennio. Questa ritrovata omogeneità territoriale ${ }^{9}$, accordando per definizione uno spazio più ampio ad Alleanza nazionale, ha sbilanciato l'alleanza verso destra ${ }^{10}$. Non si è trattato, peraltro, del solo ele-

in attesa dell'offerta più vantaggiosa. Se nel dibattito politico visibile l'attenzione era tutta rivolta a un possibile accordo tra Lega e centro-sinistra, non sembrano essere mancati negoziati più riservati tra Lega e centro-destra. Secondo l'ex ministro degli interni Maroni, ad esempio, Berlusconi offrì alla Lega un patto di desistenza già all'inizio del 1996 («Corriere della sera», 6 marzo 1996); Bossi, dal canto suo, dichiarò di aver ricevuto dal leader di Forza Italia l'offerta di 80 collegi sicuri, dieci in più del centro-sinistra, concludendo che il Polo era disposto a pagare più dell'Ulivo («L'Espresso», 18-24 marzo 1996). La decisione di chiamarsi fuori dai giochi coalizionali venne assunta da Bossi con il sostegno dei militanti e tra i mugugni di molti parlamentari leghisti, una dozzina dei quali abbandonarono il movimento andando in cerca della propria riconferma sotto altre bandiere.

8 Sul punto si rinvia a D'Alimonte e Bartolini (1996). In una conversazione con l'autore sull'andamento delle trattative al tavolo del centro-destra, l'on. Mario Tassone - delegato a quel tavolo in rappresentanza del Cdu - ha fatto riferimento a trattative tra il Polo e Rauti relative a un'ipotesi di desistenza che doveva assicurare al Movimento sociale-Fiamma tricolore sette parlamentari. Tale ipotesi sarebbe stata accantonata per l'ostinazione di Fini, intenzionato ad accordare al Movimento sociale-Fiamma tricolore non più di tre collegi ritenuti sicuri.

9 Come si ricorderà, nel 1994 alla difformità costitutiva tra Polo per le libertà e Polo del buongoverno si erano aggiunte fratture territoriali ulteriori che, in alcune circoscrizioni del Sud (Marche, Abruzzo, Molise, Campania 2 per la Camera; Abruzzo al Senato), avevano diviso il Polo del buongoverno limitandone le potenzialità competitive (Di Virgilio 1995).

10 Senza, peraltro, che ciò comportasse una radicalizzazione delle proposte della coalizione. Il divorzio dalla Lega e la minore enfasi accordata da Forza Italia a istanze 
mento a giocare in tal senso. A scoprire il fianco sinistro della coalizione hanno contribuito infatti anche altri fattori, quali la scelta di campo del presidente del consiglio Dini - al quale il centro-destra aveva dapprima proposto un impegno diretto nella coalizione, tentando più tardi di costringerlo in una posizione di «equidistanza tra $\mathrm{i}$ poli» - e lo stesso indebolimento delle posizioni più moderate all'interno di Forza Italia ${ }^{11}$. I tentativi di rafforzare il presidio di quella nevralgica area di frontiera, d'altro canto, si erano rivelati impraticabili (è il caso di Segni e dei presidenzialisti del centro-sinistra, che Berlusconi cerca invano di arruolare nel Polo), oppure privi di utilità se non dannosi (è il caso dell'insistita ricerca di un accordo con la pattuglia radicale di Pannella, «coronata» da un'intesa capziosa siglata fuori tempo massimo $)^{12}$, riducendosi, alla fin fine, alla cooptazione in Forza Italia di un manipolo di esterni di prestigio (Colletti, Melograni, Rebuffa, Vertone, gli intellettuali della Convenzione per la riforma liberale). Né, a tale scopo, appariva sufficiente l'approdo al Polo dei popolari di Buttiglione - alleati con Forza Italia alle regionali del 1995 e raccolti in seguito nel Cdu -, unico apporto aggiuntivo rispetto alla coalizione del 1994. L'arrivo di questo rinforzo ha tuttavia contribuito a modificare l'articolazione dell'alleanza, rendendone autonoma e più visibile la componente cattolica. Il tavolo coalizionale, nel 1994 a struttura rigidamente bilaterale, si è così allargato alle due anime della federazione ex-democristiana formata da Ccd e Cdu, presenti con una lista comune nell'arena proporzionale della Camera (al

liberiste sul terreno delle politiche economiche e sociali hanno anzi finito col rendere il profilo politico-programmatico del Polo per le libertà del 1996 meno dirompente (e meno divergente da quello degli avversari) rispetto agli orientamenti del Polo delle libertà del 1994 .

11 Reso evidente dall'uscita di scena di esponenti come Della Valle e Dotti, ex capigruppo forzisti a Montecitorio, questo «avvicendamento selettivo» sembra costituire una delle ragioni dell'elevato turnover imposto ai gruppi parlamentari di Forza Italia. Sul punto si rinvia all'analisi di Verzichelli (1996b).

12 Insoddisfatta dell'andamento del negoziato sulla distribuzione dei collegi, la componente radicale si era ritirata dal tavolo del Polo, presentando come Lista PannellaSgarbi 29 candidati nei collegi uninominali della Camera e 122 nei collegi senatoriali. A candidature depositate, Pannella riuscì a strappare a Berlusconi un accordo con cui otteneva dal leader di Forza Italia, in cambio di una dichiarazione di sostegno ai candidati uninominali del Polo e dell' «invito» ai propri candidati riformatori a ritirarsi dalla corsa, la promessa di un sostegno alla Lista Pannella-Sgarbi nel proporzionale, un sostegno finanziario al Movimento dei Riformatori, assicurazioni su una congrua partecipazione alla compagine dell'eventuale governo di centro-destra e l'adesione a un'ipotesi presidenzialista «all'americana» (sic!). 
contrario della componente liberaldemocratica di Costa che non riesce a proporsi come «quarta gamba» del Polo malgrado la capacità di attrazione dimostrata in sede parlamentare ${ }^{13}$ e rimane al riparo dell'ombrello forzista).

Come si è detto, a ridurre l'efficacia dell'alleanza - e, più specificamente, la sua capacità di mobilitazione elettorale - ha contribuito anche la diminuita coesione coalizionale del centrodestra. A dispetto del rapporto inverso che di solito corre tra saldezza e ampiezza di una coalizione, ciò avviene proprio nel momento in cui il nuovo formato dell'aggregazione determina una contrazione della partnership dell'alleanza. L'aspetto forse più evidente di questa ridotta coesione è fornito dalla posizione di Alleanza nazionale, che utilizza il suo più ampio margine di manovra non solo per ipotecare la linea del Polo (com'era emerso anche nell'ultimo atto della legislatura: il tentativo di Maccanico di dar vita ad un esecutivo di «larghe intese» capace di realizzare una riforma istituzionale che prendesse a riferimento il modello della Quinta Repubblica, tentativo sostenuto da Berlusconi e bocciato, con conseguente scioglimento anticipato delle camere, proprio da Fini), ma anche per lanciare la sfida ai propri alleati di schieramento ${ }^{14}$. Motivi di conflitto erano intervenuti, inoltre, anche tra i partner minori dello schieramento (ad esempio tra Ccd-Cdu e Pannella nel corso delle trattative sulla distribuzione dei collegi) e non mancavano diffidenze circa le preferenze post-elettorali delle diverse componenti della coalizione (con sospetti che si appuntavano, in particolare, su Ccd e Cdu e sulla loro presunta propensione per combinazioni parlamentari neo-centriste), né contrasti su aspetti politicoprogrammatici (dal tema delle riforme istituzionali alla questione delle privatizzazioni).

Nella sua nuova configurazione, insomma, il Polo non era più quello di due anni prima. Pur avendo dato prova di tenuta elettorale anche dopo la defezione della Lega (ad esempio, alle

13 A fine legislatura, il gruppo parlamentare dei federalisti-liberaldemocratici animato da Costa, che si era caratterizzato per un elevato indice di acquisitività accompagnato peraltro da un basso indice di fedeltà (Verzichelli 1996a), raccoglieva ben 28 deputati.

14 Nei primi giorni di campagna elettorale, ad esempio, il leader di An pose sul tappeto il problema della scelta del candidato del centro-destra alla guida del governo, mostrando evidenti riserve sul nome di Berlusconi, e non fece mistero di considerare il sorpasso di Forza Italia al proporzionale uno dei principali obiettivi del proprio partito. Si veda l'intervista rilasciata da Fini al «Corriere della sera», 19 febbraio 1996. 
elezioni regionali del 1995), la coalizione mostrava i segni di un'usura precoce. La stessa riproposizione di Berlusconi quale «candidato unico» dello schieramento per Palazzo Chigi appariva una scelta obbligata e non più, come nel 1994, un fattore di dinamismo in grado di galvanizzare l'intera coalizione e di assicurarne la compattezza ${ }^{15}$. Più specificamente, appariva evidente che l'alleanza di centro-destra non era stata in grado di sostituire gli atouts del 1994 - legati a vantaggi competitivi congiunturali e difficilmente ripetibili (la sua peculiare articolazione territoriale, l'«effetto Berlusconi», una campagna elettorale che accreditava la coalizione come espressione del «nuovo» e prospettava la realizzazione di «un nuovo miracolo italiano», i limiti e gli errori dei concorrenti) - con risorse «fresche» di altra natura, che soltanto i risultati dell'azione di governo o un processo di strutturazione partitica ${ }^{16}$ avrebbero potuto rendere disponibili.

Più innovativa, complessa e non priva di ambiguità si presenta la costruzione dell'alleanza di centro-sinistra. La coalizione (si veda la tab. 1) sommava quasi per intero i numerosi addendi che nel 1994 militavano nel cartello dei Progressisti e nel Patto per l'Italia (ne resta esclusa soltanto l'ala del partito popolare aggregatasi al Polo), acquisisce alla vigilia del voto componenti originariamente inquadrate nel Polo delle libertà (oltre a Dini, ad esempio, Sergio Berlinguer, anch'egli ex ministro del governo Berlusconi e ispiratore del Movimento italiano democratico), si estende in alcune aree a formazioni autonomistiche che nel 1994 non avevano preso parte attiva al gioco delle alleanze (il Partito Sardo d'Azione, la Lega Autonomia Veneta, l'Unione autonomista ladina). In tal modo, come si può osservare nella tabella 2, combinava ben 23 componenti partitiche (contro le sette del centro-destra), riconducibili per lo più a micro-formazioni - $\mathrm{i}$ cosiddetti «cespugli» - e soltanto in pochi

15 Rispetto alle elezioni del marzo 1994 la posizione di Berlusconi, da un lato, aveva perduto il suo carattere di eccezionalità per trasformarsi in un elemento consueto della scena politica e, dall'altro, era diventata più vulnerabile: sul fronte giudiziario, per le inchieste aperte dalla procura di Milano nei suoi confronti; per l'irrisolto «conflitto di interessi» connesso alla sua posizione imprenditoriale, che nel corso della campagna elettorale aveva indotto il segretario del Pds D'Alema a formulare nuovamente le proprie riserve circa la stessa eleggibilità del leader di Forza Italia.

16 L'osservazione vale soprattutto per Forza Italia, che in due anni non riesce a compiere alcun passo sostanziale verso la costruzione del partito liberal-conservatore di massa che sosteneva di voler diventare, incapace di por mano alle sue molteplici carenze organizzative e ai vistosi limiti del suo personale parlamentare (Maraffi 1996; Panebianco 1996b). 
casi a etichette partitiche nazionali dotate di un sufficiente grado di istituzionalizzazione organizzativa ${ }^{17}$.

Un tale «affollamento» - alimentato anche dalla diretta presenza o comunque dall'esplicito sostegno dei tecnici (fra i quali, oltre al candidato premier Prodi, dovevano annoverarsi l'ex presidente del consiglio Ciampi, l'ex presidente del consiglio incaricato Maccanico, il presidente del consiglio in carica Dini) rischiava di riproporre, con evidenza ancora maggiore, $i$ due maggiori limiti della coalizione progressista del 1994, che tanto negativamente avevano pesato sulla conduzione e sul rendimento di quel cartello elettorale: l'eccessiva ampiezza e la scarsa coerenza di un'aggregazione in cui convivevano posizioni politiche eterogenee; l'elevata densità partitica (intesa come numero $\mathrm{di}$ attori, divergenti pressioni di staff e apparati, esuberanza di personale politico in cerca di collocazione) che al tavolo coalizionale si era tradotta in paralizzanti contrasti sulla concreta messa a punto dell'intesa e in un investimento di risorse diretto più a governare la difficile convivenza infracoalizionale che non a proiettare la coalizione verso l'esterno (alla conquista dei collegi marginali, cruciali ai fini del risultato elettorale e più sensibili per definizione alle caratteristiche dell'offerta) ${ }^{18}$. Evitare il ripetersi di quella poco gloriosa esperienza ha costituito il principale incentivo all'innovazione e ha spinto le componenti della nuova alleanza elettorale - in particolare il Pds, «testa» strategica della coalizione - alla ricerca di scelte tecniche (non prive, evidentemente, di rilevanza e conseguenze politiche) in grado di ridurre $\mathrm{i}$ costi politici e decisionali connessi al formato della composita coalizione di centro-sinistra.

La tabella 2 presenta il centro-sinistra come un'aggregazio-

17 Alcune formazioni aderenti all'alleanza erano nate dopo le elezioni del 27 marzo, come frutto della dialettica parlamentare (è il caso del gruppo dei Comunisti unitari di Garavini e Crucianelli, uscito da Rifondazione comunista dopo aver votato a favore della manovra economica del governo Dini nel marzo 1995), come prosieguo della disarticolazione dei tradizionali partiti di governo e dei loro primi «eredi» (è il caso della Federazione laburista di Spini e dei Socialisti italiani di Boselli, ma, se si vuole, dello stesso Ppi di Bianco), come comitati creati allo specifico scopo di partecipare alle elezioni (è il caso di Rinnovamento italiano, la nuova formazione annunciata dal presidente del consiglio Lamberto Dini il 23 febbraio, ma anche dell'Unione democratica, la federazione dei «cespugli» laici tenuta a battesimo dall'ex presidente del consiglio incaricato Antonio Maccanico pochi giorni prima; e lo stesso può dirsi dei «Comitati per l'Italia che vogliamo» sorti a sostegno della candidatura di Prodi alla presidenza del governo a partire dalla primavera del 1995).

18 Su questi aspetti si rinvia a Di Virgilio (1995). 


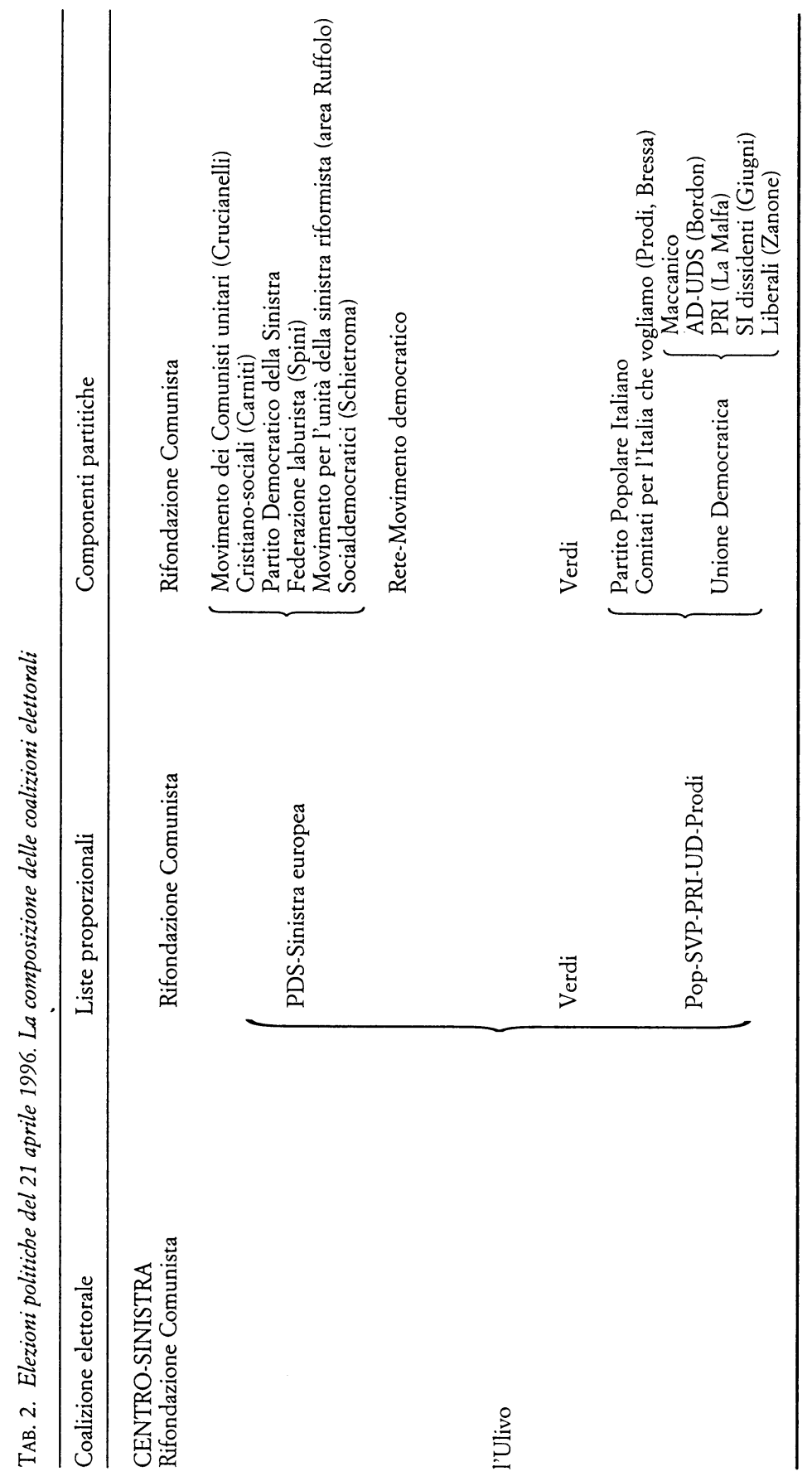




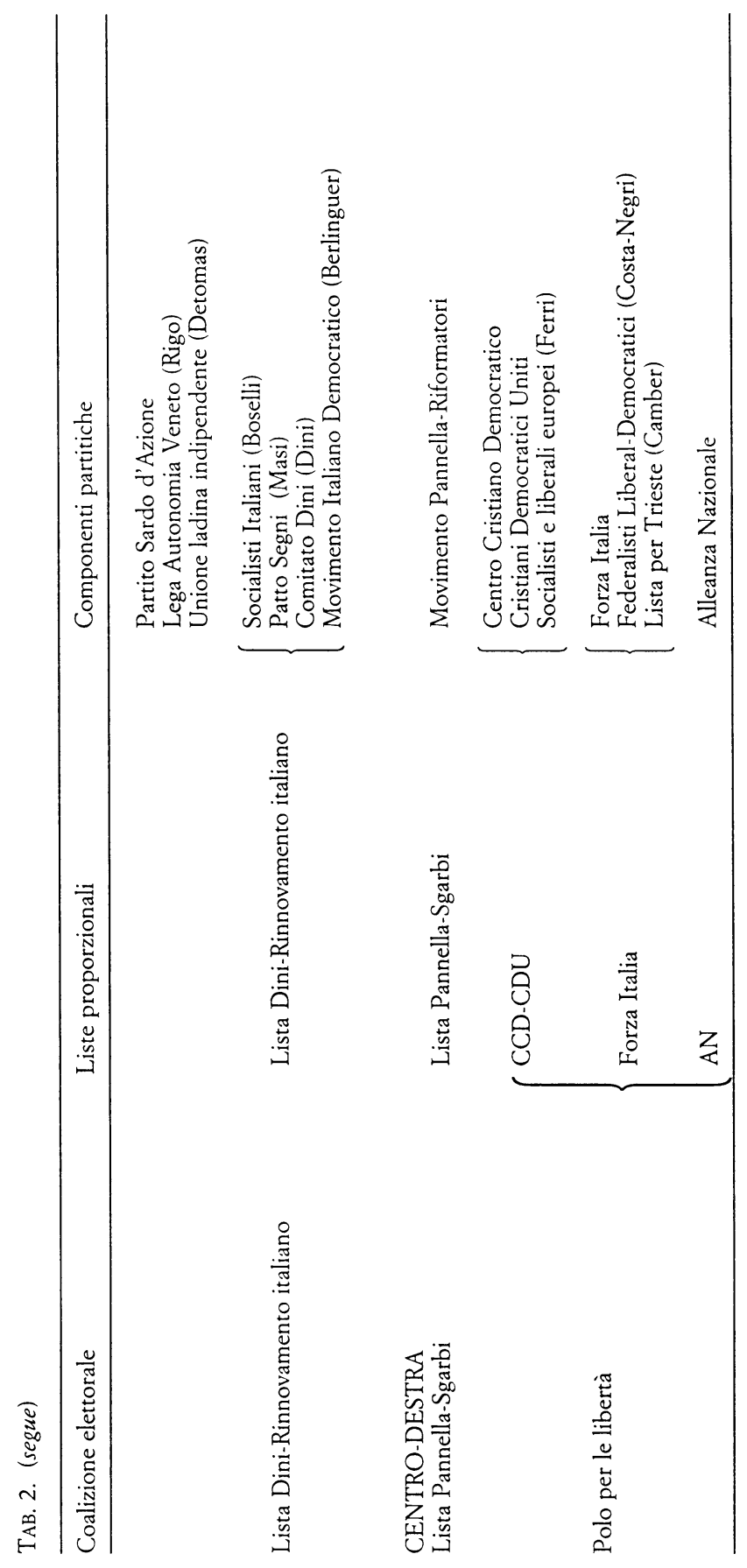


ne formata da tre elementi strutturalmente diversi: un partito (Rifondazione comunista); una coalizione assai variegata di forze (l'Ulivo), una «nuova formazione politica di centro, moderata e riformista» ${ }^{19}$ anch'essa strutturata a mo' d'arcipelago (Rinnovamento italiano-Lista Dini). Prima di esaminare le modalità secondo le quali tali elementi si sono combinati e hanno stretto alleanza, è utile ricostruire i passaggi salienti che hanno condotto al loro accordo coalizionale. Si tratta di aspetti che riflettono, da un lato, il cammino percorso dalle due coalizioni sconfitte nel 1994 e, dall'altro, la decisione di Dini di «scendere in campo», autonomamente, a fianco dell'Ulivo.

Se si osserva la configurazione della coalizione di centrosinistra per come appare nella tabella, un dato di fondo emerge con chiarezza: l'alleanza che si contrappone al polo di centrodestra non è la mera sommatoria della coalizione progressista e della coalizione centrista del 1994 , bensì il risultato di un processo di scomposizione e ricomposizione di quelle aggregazio$\mathrm{ni}^{20}$. Più specificamente, tale processo è il risultato di due dinamiche convergenti. Per un verso, dopo la sconfitta del 27 marzo e l'elezione di D'Alema alla segreteria, il Pds adotta una linea di «apertura al centro»: rinuncia di fatto alla guida del governo (mentre invece nel 1994, in caso di successo del cartello progressista, era scontato che al Pds spettasse la scelta del premier, anche se proprio la mancata indicazione di un leader costituì, per quell'alleanza, un non secondario elemento di debolezza) e decide di sostenere un candidato-premier di estrazione centrista (pur se privo di una forte identità partitica ed espressione di un'ampia coalizione di forze come Romano Prodi). Per altro verso, le forze di centro, stritolate nel 1994 dal meccanismo maggioritario (che aveva trasformato in appena quattro seggi $\mathrm{i}$ sei milioni di voti conquistati nei collegi uninominali) e alla ricerca di una ricollocazione nel gioco delle alleanze, trovarono più congeniale, con qualche residua riserva, puntare all'accordo con un Pds in movimento verso il centro anziché con un

19 E questa la definizione utilizzata da Dini nel presentare il suo partito. Si veda «Corriere della sera», 23 febbraio 1996.

20 E forse utile ricordare che nel 1994 la composizione delle aggregazioni di sinistra e di centro era la seguente: Rifondazione Comunista, Rete, Verdi, Partito Democratico della Sinistra, Rinascita Socialista, Partito Socialista, Alleanza Democratica, Cristiano-sociali per il cartello dei Progressisti; Partito Popolare Italiano e Patto Segni (a sua volta composto da Popolari per la Riforma, Partito Repubblicano, socialisti di Amato, liberali di Zanone) per il Patto per l'Italia. 
centro-destra guidato da Berlusconi e comprendente Alleanza nazionale.

Su queste premesse, tra la primavera del 1995 e la primavera del 1996, l'alleanza di centro-sinistra percorre le tappe di una lunga gestazione che ne modella, in corso d'opera, la configurazione e la partnership.

La coalizione si presenta inizialmente come un'alleanza politica tra il Pds e una progettata federazione dei «cespugli» di centro-sinistra annunciata, nei primi mesi del 1995, da tre iniziative: la costituzione del gruppo parlamentare dei Democratici, che riuniva parlamentari del Patto Segni, di Alleanza democratica e dei Socialisti italiani; il lancio dell'Ulivo come simbolo del nuovo «contenitore» politico di centro-sinistra; l'indicazione di Prodi come candidato-premier della coalizione da parte dei popolari di Bianco ${ }^{21}$. Si trattava di un'alleanza chiusa a sinistra (Rifondazione comunista non era invitata a farne parte), che sembrava doversi strutturare, sul piano elettorale, come intesa a due tra Ulivo e Pds. In questo scenario l'Ulivo si caratterizzava come l'«altro albero» della coalizione - collocato a fianco della Quercia e capace di mettere a frutto i vantaggi di posizione derivanti da tale alleanza (in primis, appunto, il riconoscimento ad esprimere dalle proprie fila il candidato-premier della coalizione) - e, quindi, come etichetta buona per la proporzionale. Nei collegi uninominali, i candidati dell'alleanza di centro-sinistra sarebbero stati, a quel punto, contrassegnati da un simbolo a doppia effigie che sancisse il sodalizio tra Ulivo e Pds.

L'inattesa «longevità» del governo Dini e il conseguente rinvio della prospettiva elettorale, l'indisponibilità dei soggetti del centro-sinistra (Popolari e Verdi in particolare) a cedere la propria autonomia, la «confluenza» del Pds nell'Ulivo contribuirono a modificare quella originaria impostazione. All'indomani delle elezioni regionali, in cui aveva dovuto affrontare per la prima volta il problema dell'estensione dei propri confini elettorali ${ }^{22}$, la coalizione di centro-sinistra aveva ormai perduto la

21 A suggerire, all'inizio del febbraio 1995, la candidatura di Prodi furono alcuni esponenti della sinistra del Ppi (Andreatta, Bianchi, Elia, Mancino, Mattarella), i quali indicando il nome dell'ex presidente dell'Iri intendevano far precipitare il chiarimento in corso all'interno del proprio partito e ostacolare la strategia del segretario Buttiglione, favorevole ad un'alleanza tra Ppi e Forza Italia.

22 In tale occasione, Rifondazione comunista partecipò in sette casi su quindici alle coalizioni di centro-sinistra (anche se soltanto in quattro casi - Lazio, Abruzzo, Molise e Puglia - di tali coalizioni facevano parte anche i popolari e/o i «cespugli» laici); la 
sua (peraltro soltanto virtuale) configurazione diarchica e assunto i connotati assembleari di un tavolo coalizionale non molto dissimile da quello progressista del 1994, in cui ciascuna componente, quale ne fosse la (in)consistenza, poteva far sentire la propria voce e imporre il proprio diritto di veto ${ }^{23}$. Ciò trasformava l'Ulivo nella «casa comune» dei numerosi membri della coalizione e, sul piano elettorale, nel simbolo-di-tutti (Pds compreso), spendibile, pertanto, non più nel proporzionale ma nel maggioritario. La coalizione trovava nella candidatura Prodi il suo denominatore comune, ma al candidato-premier, figura super partes priva di risorse organizzative autonome, i partner della coalizione sembravano riconoscere unicamente il potere di convocare il tavolo coalizionale ${ }^{24}$.

In queste condizioni, la coalizione si trovava drammaticamente esposta all'evoluzione degli eventi. Dopo le elezioni regionali la candidatura di Prodi subì un progressivo logoramento (i «Comitati per l'Italia che vogliamo», costituiti come strumento di mobilitazione in vista di una contesa elettorale ritenuta assai prossima, si trasformarono a fatica in club della coalizione, sopravvivendo grazie al decisivo sostegno del Pds) e molteplici linee di divisione si manifestarono tra i partner della coalizione (in particolare sul terreno delle riforme istituzionali). In autunno il Patto Segni e i Socialisti italiani abbandonarono formalmente l'Ulivo, seguiti a ruota dai Verdi ${ }^{25}$; all'inizio del 1996 il profilarsi di un accordo tra D'Alema e Berlusconi in vista di un governo di «larghe intese» in grado di promuovere la riforma delle istituzioni mise altrimenti a dura prova la tenuta della coalizione e

sua presenza autonoma fu decisiva per assicurare al centro-destra il governo di ben tre regioni (Piemonte, Veneto e Calabria). La Lega, che al tavolo dell'Ulivo partecipava in quei mesi con un proprio «osservatore», evitò invece qualsiasi coinvolgimento coalizionale e optò per una corsa solitaria che, nonostante il mediocre risultato del Carroccio, condizionò l'esito del voto in Piemonte, Lombardia e Veneto.

23 Su queste vicende si vedano Ignazi (1995) e Gilbert (1996).

24 Ai vertici dell'Ulivo, che si riunirono con una certa regolarità dal giugno 1995 per discutere e decidere tattiche e strategie dell'alleanza, presero parte D'Alema per il Pds, Bianco per il Ppi, Segni per il Patto Segni, Bordon per Alleanza democratica, Boselli per i Socialisti italiani, La Malfa per il Pri, Orlando per la Rete, Ripa di Meana per i Verdi, Zanone per la Federazione dei liberali, Spini per la Federazione laburista, Schietroma per il Psdi, Carniti per i Cristiano-sociali e Petrini, capogruppo leghista alla Camera, in veste di osservatore.

25 L'uscita delle tre componenti dalla coalizione avvenne a metà dicembre 1995, a ridosso della presentazione delle 88 tesi della piattaforma programmatica dell'Ulivo, alle quali Segni imputava il mancato accoglimento del presidenzialismo e i Verdi la scarsa attenzione sui temi ambientali. 
sembrò «azzerare» il ruolo dell'ex presidente dell'Iri; a metà febbraio, invece, la rinuncia di Maccanico e la convocazione di nuove elezioni ne rilanciarono le chances, tornando ad imporre l'imperativo dell'aggregazione. A quel punto la costruzione della coalizione di centro-sinistra entra in una fase nuova e decisiva, al termine della quale, attraverso alcune adeguate scelte tecnicopolitiche, un'alleanza politica in difficoltà, se non in disarmo, si trasforma in alleanza elettorale efficiente e ben congegnata. Due, principalmente, gli ingredienti di questo processo di «ingegneria coalizionale»: (a) la distinzione, all'interno dell'Ulivo, tra componenti partitiche della coalizione e liste proporzionali e l'attribuzione a queste ultime, anziché alle prime, della titolarità del negoziato coalizionale; (b) la ridefinizione della partnership e dei confini dello schieramento. L'alleanza presentava, inoltre, $(c)$ un certo grado di articolazione territoriale.

Scegliere le liste proporzionali, in luogo delle singole componenti partitiche, come espressioni principali dell'alleanza significava definire un criterio gerarchico interno, dar modo ai due principali attori della coalizione - il Pds e il Ppi - di sbarazzarsi dell'ingovernabile tavolo allargato del 1995, porre le premesse per una verticalizzazione dell'alleanza che semplificasse $\mathrm{i}$ rapporti infracoalizionali e ne riducesse $\mathrm{i}$ costi decisionali. La formazione di cartelli proporzionali, sollecitata dall'infelice esperienza del $1994^{26}$, trasformò in effetti l'alleanza in una sorta di «coalizione di coalizioni», ridusse a tre più uno il numero degli attori titolari e rese disponibili nuovi margini negoziali e possibilità di compensazione. Attorno al Pds venne a formarsi il cartello della Sinistra europea (ne facevano parte il Movimento dei comunisti unitari, la Federazione laburista, i Cristiano-sociali, il Movimento per l'unità della sinistra riformista e i socialdemocratici); fallito un tentativo di accordo con la Rete, i Verdi optarono invece per la presentazione di liste proprie; al centro della coalizione, dopo laboriose trattative, emersero, infine, due altri raggruppamenti proporzionali.

L'assetto della compagine proporzionale del centro investiva in parte anche il problema della ridefinizione della partner-

26 Alle elezioni del 1994 ben quattro liste di formazioni appartenenti alla coalizione di sinistra (Verdi, Rete, Psi e Ad) rimasero escluse dalla distribuzione dei seggi proporzionali per non aver superato il $4 \%$ dei voti validi. Le quattro formazioni dispersero oltre tre milioni di voti, pari all' $8 \%$ dei voti validi (e presumibilmente a una dozzina di deputati). 
ship e dell'estensione spaziale dello schieramento di centro-sinistra. Al centro dell'Ulivo, già di per sé non semplice da comporre per la presenza di identità, posizioni e ambizioni in competizione tra loro (ne facevano parte Prodi e il vertice dei suoi Comitati; i «cespugli» laici, nel 1994 collocati in parte nella coalizione progressista e in parte nel polo centrista; il Ppi, unica componente certa di poter contare su un seguito superiore al $4 \%$ dei voti), venne infatti a sommarsi un centro «esterno», rappresentato da Dini e dai suoi alleati ${ }^{27}$. L'indisponibilità del Ppi a rinunciare alla propria identità nell'arena proporzionale e l'esigenza di Dini di valorizzare la propria presenza in quanto apporto aggiuntivo rispetto all'Ulivo vanificarono la convergenza di tali formazioni in uno stesso cartello proporzionale. Gli attori di centro finiscono così per dar vita a due cartelli distinti (la lista Popolari-Svp-Pri-Ud-Prodi e la Lista Dini-Rinnovamento italiano), il cui assortimento registra non tanto divergenze o convergenze su issues concrete (non senza sorpresa, ad esempio, i laici federati da Maccanico nell'Unione democratica si ritrovano in lista con i popolari di Bianco, malgrado la distanza non piccola che ne separa le posizioni in tema di riforme istituzionali), ma piuttosto scelte tattiche o relative alle persone (tra queste il profilarsi di una contrapposizione tra Prodi e Dini per l'eventuale futura premiership di governo).

La formazione dei cartelli proporzionali e l'allargamento della coalizione a Dini hanno comportato una definizione negoziata anche degli elementi di presentazione grafica delle diverse componenti dell'alleanza. Il fenomeno, secondario ma non del tutto marginale, illustra con sufficiente chiarezza come anche in questo aspetto della ridefinizione dell'architettura coalizionale il criterio dell'efficacia coalizionale e l'esigenza di identità e visibilità delle singole componenti partitiche si siano intrecciati tra loro. Il Pds, ad esempio, annette al proprio simbolo la dicitura «Sinistra europea» dietro sollecitazione dei propri «cespugli», i quali, in un primo tempo, avevano preteso la soppressione dell'emblema del vecchio Pci ancora presente alle radici della Quercia. Il mancato accordo tra le componenti del cartello de-

27 A sostegno della sua iniziativa, Dini poteva contare sui «cespugli» che avevano abbandonato l'Ulivo (Patto Segni e Socialisti italiani), sull'impegno diretto di alcuni ministri del suo governo «tecnico» (Fantozzi, Ossicini, Treu), sul ralliement di alcuni parlamentari ex leghisti, tra i quali l'ex capogruppo a Montecitorio Petrini, nonché sul Mid di Sergio Berlinguer. 
termina invece la «proporzionalizzazione» del simbolo della lista proporzionale capeggiata dai popolari. Vi campeggia il gonfalone dei popolari, cui si accompagnano, con evidenza grafica crescente, l'Edelweiss del partito popolare sudtirolese, l'edera del Pri e l'emblema dell'Unione democratica di Maccanico; infine, vi si associa con evidenza - dopo che il candidato-premier ebbe accolto l'invito dei popolari a candidarsi anche al proporzionale, rinunciando al proposito di candidarsi esclusivamente nel maggioritario - la didascalia «per Prodi», in risposta alla lista «personale» messa in campo dal presidente del consiglio in carica. Gli aspetti grafici ebbero rilievo anche nel negoziato relativo al raccordo tra l'Ulivo e Rinnovamento italiano. Accantonata per il diniego del Pds l'ipotesi di desistenza avanzata in un primo tempo - ipotesi che avrebbe qualificato Rinnovamento più come «terzo polo» che non come formazione organicamente collegata con l'Ulivo -, Dini suggerì infatti, senza successo, un simbolo a doppia effigie («Ulivo-Lista Dini») corredato dalla didascalia «Alleanza per il governo», per poi accettare che i propri candidati corressero sotto il simbolo dell'Ulivo e ripiegare sulla sola didascalia, incassando a baluardo della propria autonomia il placet (e il sostegno organizzativo) del Pds alla propria autonoma presenza nell'arena proporzionale.

L'elemento grafico è intervenuto anche nell'ufficializzazione dell'accordo di desistenza tra l'Ulivo e Rifondazione comunista, altro, decisivo, ingrediente della ridefinizione della partnership e dei confini dell'alleanza di centro-sinistra. Malgrado le reiterate affermazioni relative alla «chiusura» della coalizione e le dichiarazioni dello stesso Prodi ${ }^{28}$, il ricorso a desistenze concordate con Rifondazione è apparso all'Ulivo lo strumento più idoneo per massimizzare il risultato evitando concessioni o contaminazioni sul piano politico-programmatico ${ }^{29}$. L'accordo tra Ulivo e Rifondazione si fondava infatti sul comune obiettivo di

28 Alla fine del 1995, Prodi aveva definito gli accordi di desistenza «una truffa per il paese» («Corriere della sera», 18 novembre 1995).

29 Prima che il reclutamento di Dini ne rendesse superfluo l'apporto, l'Ulivo aveva puntato a una doppia desistenza, lavorando sull'ipotesi di una desistenza a favore della Lega nella circoscrizione Lombardia 2. Nel collegio di Mirabella Eclano, invece, l'Ulivo ha desistito nei confronti di Democrazia e Libertà, sotto la cui bandiera si presentava Ciriaco De Mita (collegato alla lista Pop-Svp-Pri-Ud-Prodi). Contro De Mita ma non, come aveva in un primo tempo minacciato, nei collegi in cui l'Ulivo presentava candidati indicati da Rinnovamento italiano - era invece Rifondazione comunista a presentare un proprio candidato. 
«sconfiggere la destra» e sulla conclamata distinzione (invero non molto promettente) tra alleanza elettorale e alleanza di governo. L'impiego del simbolo Progressisti (lo stesso adottato dal cartello delle sinistre nel 1994) nei collegi uninominali in cui la coalizione di centro-sinistra era rappresentata da un esponente di Rifondazione fissava anche visivamente i termini dell'accordo e avvalorava la posizione dell'Ulivo secondo la quale un tale accordo doveva favorire il conseguimento di una «maggioranza parlamentare autosufficiente» (non ipotecata, cioè, da Rifondazione). La differenziazione del simbolo consentiva, inoltre, un migliore controllo delle interconnessioni tra maggioritario e proporzionale - in particolare al Senato, dove, per effetto dello «scorporo totale» e della scheda unica, l'intreccio tra le due arene produceva conseguenze meno prevedibili -, evitando che lo scorporo prodotto da candidati vincenti di Rifondazione potesse ricadere sulle altre componenti della coalizione ${ }^{30}$.

Un'ultima caratteristica della coalizione di centro-sinistra, come si è detto, è stata il suo adattamento ad alcune specifiche condizioni locali. Senza trattarsi di un profilo determinante, segnala tuttavia una differenza rispetto alle elezioni del 1994 (alle quali i progressisti, così come il polo di centro, parteciparono con un formato territorialmente omogeneo) che consente alla coalizione di integrare, «fuori quota» rispetto agli allineamenti illustrati fin qui, tre formazioni autonomistiche: la Lega Autonomia Veneta, il Partito Sardo d'Azione, l'Unione autonomista ladina ${ }^{31}$.

Riassumendo, l'esame della composizione delle coalizioni del 21 aprile e del processo di costruzione di tali alleanze ha posto in evidenza come neanche questa volta, nonostante la lezione del 1994, le aggregazioni elettorali abbiano badato a massimizzare coesione e coerenza programmatica ${ }^{32}$. In questa occasione ciò vale soprattutto per il centro-sinistra che, a differenza del Polo per le libertà, si caratterizza geneticamente come car-

$30 \mathrm{La}$ formula adottata per il Senato è stata la presentazione dei candidati progressisti come candidati indipendenti, esclusi quindi dal riparto proporzionale dei seggi.

31 In Veneto e in Sardegna, i candidati dell'Ulivo si presentano, rispettivamente, con il simbolo l'Ulivo-Lav e l'Ulivo-Psd'a. Nei collegi altoatesini e in quelli trentini, invece, corrono contro l'Ulivo, rispettivamente, i candidati della Svp e del Patt-l'Abete, gli uni e gli altri collegati alla lista Pop.-Svp-Pri-Ud-Prodi.

$32 \mathrm{La}$ sconsolata osservazione di Giuliano Urbani di fronte alla rissosità degli schieramenti alla vigilia del negoziato sulla ripartizione dei collegi è che le alleanze si sono ormai ridotte a «poli di pastafrolla» («Corriere della sera», 15 febbraio 1996). 
tello costruito contro un comune avversario anziché proporsi come maggioranza programmatica e di governo. Pur lasciando irrisolto il nodo del governo, la coalizione di centro-sinistra presenta tuttavia modalità di coalition building che le consentono di orchestrare le 23 voci che la compongono evitando di apparire meno coesa del Polo per le libertà. L'accordo di desistenza con Rifondazione comunista sdrammatizza i problemi di estensione ideologica dell'aggregazione, salvaguardando la massimizzazione del risultato. L'investimento strategico sulle interazioni tra competizione proporzionale e competizione maggioritaria, a sua volta, permette di semplificare la conduzione della coalizione, di dissimulare - nel caso dell'accordo tra l'Ulivo e Dini - la realtà dell'alleanza con l'apparenza dell'autonomia (Panebianco 1996a), di esternalizzare alcuni costi coalizionali - è il caso della competizione tra Prodi e Dini per l'eventuale futura premiership di governo - scaricandoli sul verdetto delle urne (nel caso specifico il risultato che la lista Popolari per Prodi e la Lista Dini avrebbero ottenuto al proporzionale). Lungo queste dimensioni, il centro-destra appare poco innovativo rispetto al 1994 e tuttavia, al tempo stesso, sufficientemente mutato («in peggio», quanto a grado di adeguatezza alla struttura dei vincoli e delle opportunità definita dalla legge elettorale) da poter essere ragionevolmente considerato, alla vigilia del voto, «candidato alla sconfitta» ${ }^{33}$.

\section{Il modus operandi delle alleanze: cosa è cambiato?}

Nel 1994 la genesi e la composizione delle alleanze elettorali avevano influenzato in vario modo i rapporti infracoalizionali. Nel caso dell'accordo inerente la distribuzione dei collegi uninominali fra le componenti partitiche delle alleanze e la selezione dei candidati - principale punto di osservazione delle relazioni tra i partner coalizionali e, quindi, dei criteri di regolazione prevalenti in ciascuno schieramento - era emerso, ad esempio, il peso di fattori quali il numero degli attori rilevanti, le loro propensioni latu senso culturali ${ }^{34}$, il grado di uniformità 1996.

33 Il giudizio è espresso da Mino Fuccillo su «la Repubblica», 26 e 29 febbraio

34 La proporzionalizzazione dell'alleanza progressista, ad esempio, rispecchiava la preponderanza di un personale politico e di apparati partitici legati, per socializzazione 
territoriale dell'intesa, le sedi e i livelli della trattativa. Tali fattori avevano contribuito a definire i termini dell'accordo coalizionale, condizionato tempi e modi dei processi decisionali infracoalizionali, influito, in ultima istanza, sullo stesso rendimento elettorale della coalizione (Di Virgilio 1995).

Rispetto a quella prima esperienza, le elezioni del 1996 presentano più di una novità. Le innovazioni principali provengono, anche a questo proposito, dalla coalizione di centro-sinistra, che, soprattutto per impulso del Pds, realizza alcune decisive correzioni di rotta, dimostrando una capacità di apprendimento dalla fallimentare prova del 1994 forse inaspettata. Nel caso del centro-destra, le relazioni infracoalizionali risentono invece negativamente di una carenza di leadership coalizionale, risorsa che due anni prima si era rivelata decisiva, e l'andamento delle trattative per la risoluzione del rompicapo dei collegi uninominali si adatta a queste nuove condizioni.

Per il centro-destra, peraltro, il quadro dei rapporti coalizionali si presentava oggettivamente più difficile da almeno due punti di vista. In primo luogo, i partner coalizionali non sono più attori nuovi (Forza Italia) $o$ in attesa di un'affermazione consistente e ragionevolmente sicura (An), bensì formazioni alla ricerca di una non scontata conferma della propria forza elettorale e parlamentare e in lotta tra loro per la conquista della supremazia di schieramento. Inoltre, come si è detto, l'intesa coalizionale, siglata nel 1994 ad un tavolo centralizzato e rigidamente bilaterale, è resa più complessa dalla partecipazione di due nuovi attori - il Ccd e il $\mathrm{Cdu}^{35}$-, ai quali, in momenti successivi, si aggiungono Pannella (nella prima fase del negoziato e fino alla sua rottura con il Polo) e Costa (nell'ultima settimana di trattative, in qualità di osservatore, come rappresentante della componente federalista-liberaldemocratica). Un terzo elemento - l'uscita della Lega dalla scena coalizionale - introduceva

e consuetudine, a metodi e logiche proporzionalistiche e costituiva il criterio più consono a una coalizione affollata, le cui componenti avevano negoziato almeno formalmente su un piede di parità. La configurazione dell'offerta coalizionale del centro-destra, e il prevalere al suo interno di criteri compensatori, risentivano invece della trasposizione nell'arena elettorale di tecniche e modalità mutuate dalle strategie commerciali adottate dal gruppo Fininvest fino a quel momento.

35 Pur presentando liste comuni per la proporzionale ed essendo da tempo in procinto di federarsi, le due formazioni della componente cattolica del Polo partecipano al tavolo come attori distinti, non sempre caratterizzati da un indirizzo comune. 
invece nel negoziato un potenziale elemento di flessibilità, in quanto «liberava» nelle circoscrizioni settentrionali 232 collegi (160 dei quali conquistati nel 1994 dal Polo per le libertà).

La definizione di un metodo in base al quale distribuire $\mathrm{i}$ collegi tra le componenti ha impegnato a lungo il «tavolo» del Polo. Se il criterio della conferma degli uscenti (i collegi, non necessariamente le persone) non ha trovato sostanziali opposizioni (salvo alcune resistenze del $\mathrm{Cdu}$ che se ne vedeva penaliz$z^{2}{ }^{36}{ }^{3}$ ), la determinazione del peso specifico delle singole componenti si rivela piuttosto conflittuale. Scartata la richiesta di An di tener conto, nella distribuzione delle spoglie, anche dell'andamento delle inchieste di opinione (che, nei primi mesi del 1996, avvaloravano una crescita del partito di Fini nelle intenzioni di voto) e la proposta del Cdu di affidare a Forza Italia il compito di tirare le fila della trattativa attraverso una serie di incontri bilaterali con le singole componenti, il negoziato assume come principale criterio di riferimento i risultati del voto regionale del 1995. Su questa base, che lasciava il Cdu ai margini della trattativa ${ }^{37}$, le parti si sono accordate per una ripartizione proporzionale delle spoglie, integrata e corretta da criteri di compensazione territoriale ${ }^{38}$.

Come si può ricavare dai dati riportati nelle tabelle 3 e 4 in cui la ripartizione dei collegi uninominali di Camera e Senato fra le componenti del Polo è riportata in un riepilogo per circoscrizione e per area geopolitica (il Nord, senza l'Emilia Romagna; la Zona rossa; il Sud, Lazio compreso) - ai valori medi corrispondono significative variazioni territoriali. Nei collegi del

$36 \mathrm{Al}$ momento della scissione che divise il partito in due, i parlamentari popolari optarono in prevalenza per Bianco, lasciando il Cdu «sottorappresentato» in sede parlamentare.

37 Alle elezioni regionali, il partito di Buttiglione aveva infatti presentato liste comuni con Forza Italia e valutarne l'effettiva consistenza era impresa ardua (anche perché in quell'occasione, giocando sul voto di preferenza, aveva eletto, con sgradita sorpresa dell'alleato, un numero assai elevato di consiglieri: Di Virgilio 1996, 80-82). Al tavolo del Polo, il Cdu si è visto così convenzionalmente attribuito un peso analogo al Ccd.

38 Alle elezioni regionali dell'aprile 1995, il risultato delle singole componenti del centro-destra nella competizione proporzionale era stato il seguente: Forza Italia-Polo popolare 22,3\%; An 14,4\%; Ccd 4,2\%. Le liste Forza Italia-Polo popolare avevano pertanto raccolto il 54,5\% del voto del centro-destra, An il $35,2 \%$ e il Ccd il 10,3\%. A candidature depositate (si vedano le tabb. 3 e 4) Forza Italia (federalisti-liberaldemocratici compresi) contava per poco meno della metà dei collegi uninominali di Camera e Senato, An per circa un terzo, il Ccd e il Cdu per il restante $18 \%$. 
TAB. 3. Centro-destra: appartenenza partitica dei candidati. Camera dei deputati

\begin{tabular}{|c|c|c|c|c|c|c|c|}
\hline Circoscrizione & & AN & Forza Italia & FLD & $\mathrm{CCD}$ & CDU & Totale \\
\hline Piemonte 1 & & 5 & 11 & 1 & 2 & & 19 \\
\hline Piemonte 2 & & 5 & 10 & 1 & & 1 & 17 \\
\hline Lombardia 1 & & 6 & 19 & 3 & 1 & 2 & 31 \\
\hline Lombardia 2 & & 8 & 18 & 2 & 1 & 3 & 32 \\
\hline Lombardia 3 & & 2 & 6 & 2 & 1 & & 11 \\
\hline Trentino-Alto Adige & & 2 & 4 & & 1 & 1 & 8 \\
\hline Veneto 1 & & 5 & 13 & 1 & 2 & 1 & 22 \\
\hline Veneto 2 & & 4 & 9 & & 2 & & 15 \\
\hline Friuli-Venezia Giulia & & 3 & $5^{a}$ & & 1 & 1 & 10 \\
\hline Liguria & & 2 & 7 & & 2 & 3 & 14 \\
\hline NORD & $\begin{array}{l}\mathrm{n}^{\circ} \\
\%\end{array}$ & $\begin{array}{l}42 \\
23,5\end{array}$ & $\begin{array}{l}102 \\
57,0\end{array}$ & $\begin{array}{l}10 \\
5,6\end{array}$ & $\begin{array}{l}13 \\
7,2\end{array}$ & $\begin{array}{l}12 \\
6,7\end{array}$ & $\begin{array}{l}179 \\
100\end{array}$ \\
\hline Emilia Romagna & & 10 & 13 & & 4 & 5 & 32 \\
\hline Toscana & & 8 & 12 & & 2 & 7 & 29 \\
\hline Umbria & & 4 & 3 & & & & 7 \\
\hline Marche & & 5 & 5 & & 1 & 1 & 12 \\
\hline \multirow[t]{2}{*}{ ZONA ROSSA } & $\mathrm{n}^{\circ}$ & 27 & 33 & & 7 & 13 & 80 \\
\hline & $\%$ & 33,75 & 41,25 & & 8,75 & 16,25 & 100 \\
\hline Lazio 1 & & 13 & 13 & & 3 & 3 & 32 \\
\hline Lazio 2 & & 5 & 6 & & & & 11 \\
\hline Abruzzi & & 4 & 5 & & 1 & 1 & 11 \\
\hline Molise & & 1 & 1 & & & 1 & 3 \\
\hline Campania 1 & & 9 & 10 & & 4 & 2 & 25 \\
\hline Campania 2 & & 8 & 7 & & 6 & 1 & 22 \\
\hline Puglia & & 21 & 9 & & 2 & 2 & 34 \\
\hline Basilicata & & 2 & 3 & & & & 5 \\
\hline Calabria & & 8 & 6 & & 2 & 1 & 17 \\
\hline Sicilia 1 & & 6 & 10 & & 1 & 3 & 20 \\
\hline Sicilia 2 & & 11 & 8 & & 2 & & 21 \\
\hline Sardegna & & 5 & 8 & & & 1 & 14 \\
\hline \multirow[t]{2}{*}{ SUD } & $\mathrm{n}^{\circ}$ & 93 & 86 & & 21 & 15 & 215 \\
\hline & $\%$ & 43,2 & 40,0 & & 9,8 & 7,0 & 100 \\
\hline \multirow[t]{2}{*}{ ITALIA } & $\mathrm{n}^{\circ}$ & 162 & 221 & 10 & 41 & 40 & 474 \\
\hline & $\%$ & 34,2 & 46,6 & 2,1 & 8,7 & 8,4 & 100 \\
\hline
\end{tabular}

a Di cui un candidato (eletto) per la Lista per Trieste.

Fonte: Elaborazione propria su dati pubblicati da «Il Secolo d'Italia», 31 marzo 1996 e su dati forniti dall'Ufficio organizzazione dei Cristiani Democratici Uniti.

Nord, ad esempio, Forza Italia rileva larga parte dei collegi attribuiti nel 1994 alla Lega e assume, almeno sul piano quantitativo, una posizione di assoluta preminenza, assicurandosi poco meno dei due terzi dei collegi, una piccola parte dei quali «gira- 
TAB. 4 . Centro-destra: appartenenza partitica dei candidati. Senato della Repubblica

\begin{tabular}{|c|c|c|c|c|c|c|c|c|}
\hline \multicolumn{2}{|l|}{ Circoscrizione } & AN & Forza Italia & FLD & CCD & $\mathrm{CDU}$ & Indipendenti & Totale \\
\hline \multicolumn{2}{|l|}{ Piemonte } & 2 & 10 & & 3 & 2 & & 17 \\
\hline \multicolumn{2}{|l|}{ Lombardia } & 10 & 21 & 2 & 1 & 1 & & 35 \\
\hline \multicolumn{2}{|l|}{ Trentino-Alto Adige } & 2 & 1 & 1 & 1 & 1 & & 6 \\
\hline \multicolumn{2}{|l|}{ Veneto } & 4 & 12 & & 1 & & & 17 \\
\hline \multicolumn{2}{|l|}{ Friuli-Venezia Giulia } & 1 & $3 a$ & & 1 & & & 5 \\
\hline \multicolumn{2}{|l|}{ Liguria } & 2 & 3 & 1 & & & & 6 \\
\hline \multirow[t]{2}{*}{ NORD } & $n^{\circ}$ & 21 & 50 & 4 & 7 & 4 & & 86 \\
\hline & $\%$ & 24,4 & 58,1 & 4,7 & 8,1 & 4,7 & & 100 \\
\hline \multicolumn{2}{|l|}{ Emilia Romagna } & 6 & 7 & & 1 & 1 & & 15 \\
\hline \multicolumn{2}{|l|}{ Toscana } & 7 & 5 & & 1 & 1 & & 14 \\
\hline \multicolumn{2}{|l|}{ Umbria } & 2 & 2 & & & 1 & & 5 \\
\hline \multicolumn{2}{|l|}{ Marche } & 2 & 3 & & & 1 & & 6 \\
\hline \multirow[t]{2}{*}{ ZONA ROSSA } & $\mathrm{n}^{\circ}$ & 17 & 17 & & 2 & 4 & & 40 \\
\hline & $\%$ & 42,5 & 42,5 & & 5,0 & 10,0 & & 100 \\
\hline \multicolumn{2}{|l|}{ Lazio } & 13 & 4 & & 4 & & & 21 \\
\hline \multicolumn{2}{|l|}{ Abruzzi } & 1 & 3 & & 1 & & & 5 \\
\hline \multicolumn{2}{|l|}{ Molise } & 1 & & & 1 & & & 2 \\
\hline \multicolumn{2}{|l|}{ Campania } & 8 & 9 & & 4 & 1 & & 22 \\
\hline \multicolumn{2}{|l|}{ Puglia } & 6 & 5 & & 1 & 4 & & 16 \\
\hline \multicolumn{2}{|l|}{ Basilicata } & 1 & 1 & & 2 & 1 & & 5 \\
\hline \multicolumn{2}{|l|}{ Calabria } & 2 & 3 & & 1 & 2 & & 8 \\
\hline \multicolumn{2}{|l|}{ Sicilia } & 5 & 7 & & 4 & 1 & 3 & 20 \\
\hline \multicolumn{2}{|l|}{ Sardegna } & 2 & 2 & & 1 & 1 & & 6 \\
\hline \multirow[t]{2}{*}{ SUD } & $\mathrm{n}^{\circ}$ & 39 & 34 & & 19 & 10 & 3 & 105 \\
\hline & $\%$ & 37,1 & 32,4 & & 18,1 & 9,5 & 2,9 & 100 \\
\hline \multirow[t]{2}{*}{ ITALIA } & $\mathrm{n}^{\circ}$ & 77 & 101 & 4 & 28 & 18 & 3 & 231 \\
\hline & $\%$ & 33,4 & 43,7 & 1,7 & 12,1 & 7,8 & 1,3 & 100 \\
\hline
\end{tabular}

a Di cui un candidato (eletto) per la Lista per Trieste.

Fonte: Elaborazione propria su dati pubblicati da «Il Secolo d'Italia», 31 marzo 1996 e su dati forniti dall'Ufficio organizzazione dei Cristiani Democratici Uniti.

ti» alla componente federalista-liberaldemocratica. Al Sud, il partito con il maggior numero di candidati è invece Alleanza nazionale. La supremazia di An appare peraltro ridimensionata rispetto alle elezioni di due anni prima (An esprimeva oltre la metà dei candidati del Polo del buongoverno; questa volta, in quelle stesse circoscrizioni, riesce a imporre un proprio candidato nel 43,6\% dei collegi uninominali della Camera e nel $38 \%$ dei collegi uninominali del Senato). In cambio di una presenza non trascurabile nei collegi uninominali del Nord (pari a poco meno di un quarto dei candidati), il partito di Fini deve infatti 
cedere agli alleati, a titolo di compensazione territoriale, 20 collegi conquistati nel 1994 per il Polo del buongoverno (trasferendone undici a Forza Italia, sei al Ccd e tre al Cdu ${ }^{39}$. La componente cattolica, a sua volta, passa da 56 a 127 candidature, incrementando la propria quota al Nord e nella Zona rossa, in quest'ultimo caso soprattutto alla Camera, dove la presenza nei collegi uninominali si rivela un utile elemento di mobilitazione del voto proporzionale (che, nella Zona rossa, apporta alla lista Ccd-Cdu tre seggi). Le due formazioni ex democristiane si dividono tali candidature seguendo il profilo del rispettivo insediamento territoriale che presenta limitate aree di intersezione (Lazio, Calabria e Sicilia) e una sostanziale complementarietà (preponderante presenza del Ccd in Piemonte, Emilia Romagna e Campania; del Cdu in Lombardia, Toscana e Puglia).

I dati delle tabelle 3 e 4 confermano dunque che, nel passaggio 1994-1996, il centro-destra subisce alcuni significativi mutamenti. L'uniformità territoriale dello schieramento e l'assenza di un riconosciuto coalition maker (come, due anni prima, Forza Italia) favoriscono una regolazione sostanzialmente proporzionalistica dei rapporti infracoalizionali. In questo tipo di trattativa, ciascuna componente antepone il rispettivo interesse partitico al più generale interesse coalizionale, rendendo il negoziato più difficile che nel 1994. Se Forza Italia appare meno arrendevole nei confronti degli alleati - e non più disposta alle concessioni che due anni prima ne avevano esaltato la funzione di baricentro dello schieramento, sminuendone però la consistenza parlamentare -, è tuttavia An a condurre il gioco negoziale, decidendo l'ordine delle circoscrizioni da prendere in esame (prima il Nord e poi il Sud) e assicurandosi, anche nelle circoscrizioni settentrionali, un elevato numero di collegi ritenuti sicuri (si veda, più avanti, la tab. 12). Come nel 1994, la trattativa sui collegi si è svolta in modo centralizzato, contemplando solo interventi sporadici in merito alla selezione dei candidati,

39 Il quadro degli «scambi di collegio» tra le componenti del Polo per le libertà si presenta assai articolato. In Puglia, ad esempio, passano di mano dieci collegi sui 32 conquistati dal centro-destra nel 1994, in Sicilia 11 su 54, nel Lazio otto su 56, in Campania sei su 17: complessivamente oltre un quarto del totale. In questa girandola, An paga il prezzo più elevato: nelle quattro regioni in questione cede infatti venti collegi (11 alla Camera e 9 al Senato), 18 dei quali vengono conquistati dal centro-destra anche nel 1996 (sette su otto in Puglia, sei in Sicilia, tre su quattro in Campania e due nel Lazio); ne riceve tre dal Ccd (due al Senato, in Sicilia e nel Lazio; uno alla Camera, in Campania), tutti perduti. 
TAB. 5. Centro-destra: rendimento dei candidati nei collegi uninominali per appartenenza partitica

\begin{tabular}{|c|c|c|c|c|c|c|}
\hline & AN & Forza Italia & FLD & CCD & $\mathrm{CDU}$ & Totale \\
\hline \multicolumn{7}{|l|}{$N^{\circ}$ eletti alla Camera: } \\
\hline $\begin{array}{l}\text { Nord } \\
\text { Zona rossa } \\
\text { Sud }\end{array}$ & $\begin{array}{r}16 \\
1 \\
48\end{array}$ & $\begin{array}{r}38 \\
2 \\
41\end{array}$ & $\begin{array}{l}5 \\
- \\
-\end{array}$ & $\begin{array}{r}2 \\
11\end{array}$ & $\frac{1}{4}$ & $\begin{array}{r}62 \\
3 \\
104\end{array}$ \\
\hline $\begin{array}{l}\text { Italia } \\
\text { tasso di rendimento }\end{array}$ & $\begin{array}{l}65 \\
40,1\end{array}$ & $\begin{array}{l}81 \\
36,7\end{array}$ & $\begin{array}{c}5 \\
50,0\end{array}$ & $\begin{array}{l}13 \\
31,7\end{array}$ & $\begin{array}{c}5 \\
12,5\end{array}$ & $\begin{array}{l}169 \\
35,7\end{array}$ \\
\hline \multicolumn{7}{|l|}{$N^{\circ}$ eletti al Senato: } \\
\hline $\begin{array}{l}\text { Nord } \\
\text { Sud }\end{array}$ & $\begin{array}{r}8 \\
20\end{array}$ & $\begin{array}{l}11 \\
12\end{array}$ & 1 & $\begin{array}{l}2 \\
7\end{array}$ & $\begin{array}{l}2 \\
4\end{array}$ & $\begin{array}{l}24 \\
43\end{array}$ \\
\hline $\begin{array}{l}\text { Italia } \\
\text { tasso di rendimento }\end{array}$ & $\begin{array}{l}28 \\
36,4\end{array}$ & $\begin{array}{l}23 \\
22,8\end{array}$ & $\begin{array}{c}1 \\
25,0\end{array}$ & $\begin{array}{c}9 \\
32,1\end{array}$ & $\begin{array}{c}6 \\
33,3\end{array}$ & $\begin{array}{l}67 \\
29,4\end{array}$ \\
\hline
\end{tabular}

Fonte: Si vedano le tabelle 3 e 4.

demandata sostanzialmente alle autonome scelte di ciascuna componente $e^{40}$.

Al diverso andamento del negoziato infracoalizionale ha corrisposto una sostanziale continuità nel rendimento relativo delle singole componenti dello schieramento. Se la sconfitta fa precipitare il tasso di successo della coalizione al 35,7\% nei collegi della Camera e addirittura al $29 \%$ nei collegi del Senato ${ }^{41}$, i candidati di Alleanza nazionale registrano infatti, anche questa volta, un rendimento superiore alla media (al Sud, in particolare, conquistano il seggio in oltre la metà dei casi) e migliore anche nelle circoscrizioni del Nord (soprattutto al Senato) a quello dei candidati di Forza Italia. Nei collegi del Sud, anche i candidati del Ccd - ma non quelli del Cdu - ottengono un risulta-

40 Anche in questa occasione, tra Forza Italia e i suoi alleati si sono registrate significative differenze, per il carattere partitico della selezione dei candidati di An - che ha seguito come criterio prevalente la riconferma dei parlamentari uscenti - e delle componenti ex democristiane - che hanno puntato, invece, alla promozione parlamentare dei loro dirigenti centrali - e il permanere dell' «eccezionalità» forzista.

41 Nel 1994 i valori erano del $90,9 \%$ alla Camera e dell' $84,9 \%$ al Senato per il Polo per le libertà e del 71,3\% alla Camera e del 54,5\% al Senato per il Polo del buongoverno. 
to relativo piuttosto positivo, mentre i candidati di Forza Italia fanno meglio della media di schieramento soltanto nei collegi della Camera al Nord.

Nello schieramento di centro-sinistra, come si è detto, l'intesa sulla ripartizione dei collegi tra le componenti coalizionali presenta, rispetto al 1994, significative differenze. In primo luogo, smessi i litigiosi e pletorici «tavoli» regionali di due anni prima, la trattativa è condotta interamente a livello centrale. Il negoziato, inoltre, si è articolato su più livelli: il tavolo dell'Ulivo, cui prendevano parte i rappresentanti del Pds, dei Verdi, del Ppi e della Lista Dini, più Prodi in qualità di candidatopremier; il tavolo bilaterale tra Pds e Rifondazione, attorno al quale sono stati definiti i termini della desistenza tra l'Ulivo e $\mathrm{Rc}^{42}$; i tavoli dei cartelli proporzionali, utilizzati dalle componenti delle singole liste per definire le rispettive sottoquote di candidati. Il negoziato sui collegi, con un'opzione intesa anch'essa a semplificare la trattativa e ad elidere potenziali motivi di conflitto, è stata infine tenuta per lo più separata dalle scelte relative alle persone. Mentre nel 1994 il tavolo centrale del cartello progressista si era riservato la libera allocazione di una quota di «candidature nazionali», «paracadutate» in collegi sicuri, in questa occasione lo schieramento ha demandato la selezione dei candidati alle singole componenti, le quali vi hanno provveduto in modo autonomo, con criteri che ne rispecchiano il diverso grado di strutturazione partitica ${ }^{43}$.

Su queste basi, la coalizione definisce, al tavolo dell'Ulivo, una ripartizione di massima dei collegi uninominali che assegnava il $60 \%$ delle candidature alla sinistra (Rifondazione compresa) e il $40 \%$ al centro (Verdi compresi). Tale suddivisione riproduceva solo in via tendenziale i rapporti di forza elettorali delle elezioni regionali, riconoscendo al centro un peso superio-

42 Secondo l'on. Mauro Zani - uno dei dirigenti ai quali il Pds ha affidato l'istruttoria delle candidature - «un tavolo Ulivo-Rifondazione era impensabile e non avrebbe portato a nulla».

43 Due le (vistose) eccezioni a questo modo di procedere: la scelta di non accogliere De Mita, proposto dai popolari, tra i candidati della coalizione; il rifiuto di candidare Dotti, per il quale Dini aveva fatto richiesta di un collegio in quota Rinnovamento italiano nel Monferrato. Il criterio dell'autonoma scelta dei candidati da parte delle singole componenti è stato in parte bilanciato, su sollecitazione del Pds, dallo scrutinio coalizionale dei candidati destinati a presentarsi nei collegi ritenuti marginali. C'è da chiedersi se l'assenza di un criterio di selezione coalizionale dei candidati non renda poco plausibile considerare l'«effetto candidato» come elemento esplicativo del risultato del voto e, in particolare, del buon risultato ottenuto dal centro-sinistra nella competizione maggioritaria. 
re alla sua effettiva consistenza ${ }^{44}$, con un premio che, al termine delle trattative, risultava ancor più significativo (in particolare alla Camera, dove il centro si assicura il $45 \%$ dei candidati). Come si può leggere nelle tabelle 6 (Camera) e 7 (Senato), la divisione degli oltre 700 collegi tra le numerose componenti dell'alleanza dà luogo a un quadro assai articolato, risultato di un complesso gioco ad incastri. Rifondazione comunista, che rispetto al 1994 dimezza il proprio pacchetto, riesce ad ottenere la conferma di larga parte dei collegi conquistati due anni prima - facendovi sloggiare il parlamentare uscente se transfuga passato al Movimento dei comunisti unitari - e concentra così la propria presenza nelle circoscrizioni della Zona rossa. Il Pds, nonostante l'estensione della coalizione, si assicura un numero di candidature superiore a quello di due anni prima, uscendo assai bene dal negoziato. Il maggior partito dello schieramento mantiene una salda presa sui collegi dell'Italia centrale e, per il resto, redistribuisce la propria presenza in modo da assecondare le esigenze dei partner coalizionali, badando peraltro a garantire ai «cespugli» della Sinistra europea l'elezione dei rispettivi stati maggiori. Anche i Verdi riescono a mantenere le posizioni di due anni prima (passano da 46 a 43 candidati), mentre più complessa si presenta la distribuzione delle candidature tra le due liste e le molte componenti dichiaratamente collocate al centro. L'ipotesi di conferire pari dignità ai due centri della coalizione attribuendo loro lo stesso numero di candidati - ipotesi avanzata da Dini al momento della sua scelta di campo e avvalorata dal Pds - si perde nel corso della trattativa. Dopo aver giocato con efficacia i tempi e i modi della sua strategia personale, il presidente del consiglio in carica patisce infatti prevedibili difficoltà nell'edificazione del proprio movimento politico. I limiti di Rinnovamento, compagine priva di expertise e di una salda linea negoziale, emergono così nel corso della trattativa con piena evidenza, lasciando campo libero alla consumata professionalità politica messa in campo dai popolari (rappresentati al tavolo da Marini). Otre a spostare a proprio

44 Alle elezioni regionali dell'aprile 1995 , nella competizione proporzionale, Rifondazione comunista aveva ottenuto l' $8,4 \%$ dei voti, il Pds il $25,4 \%$, i Verdi il $3 \%$ e le numerose combinazioni centriste (cui partecipava in alcuni casi anche un Ppi nel bel mezzo della scissione) l' $11,8 \%$. Il Pds e Rifondazione vantavano, pertanto, il $69 \%$ della forza elettorale dello schieramento (il $17,1 \%$ Rc, il $51,9 \%$ il Pds), mentre le formazioni di centro non andavano al di là del $32 \%$. 


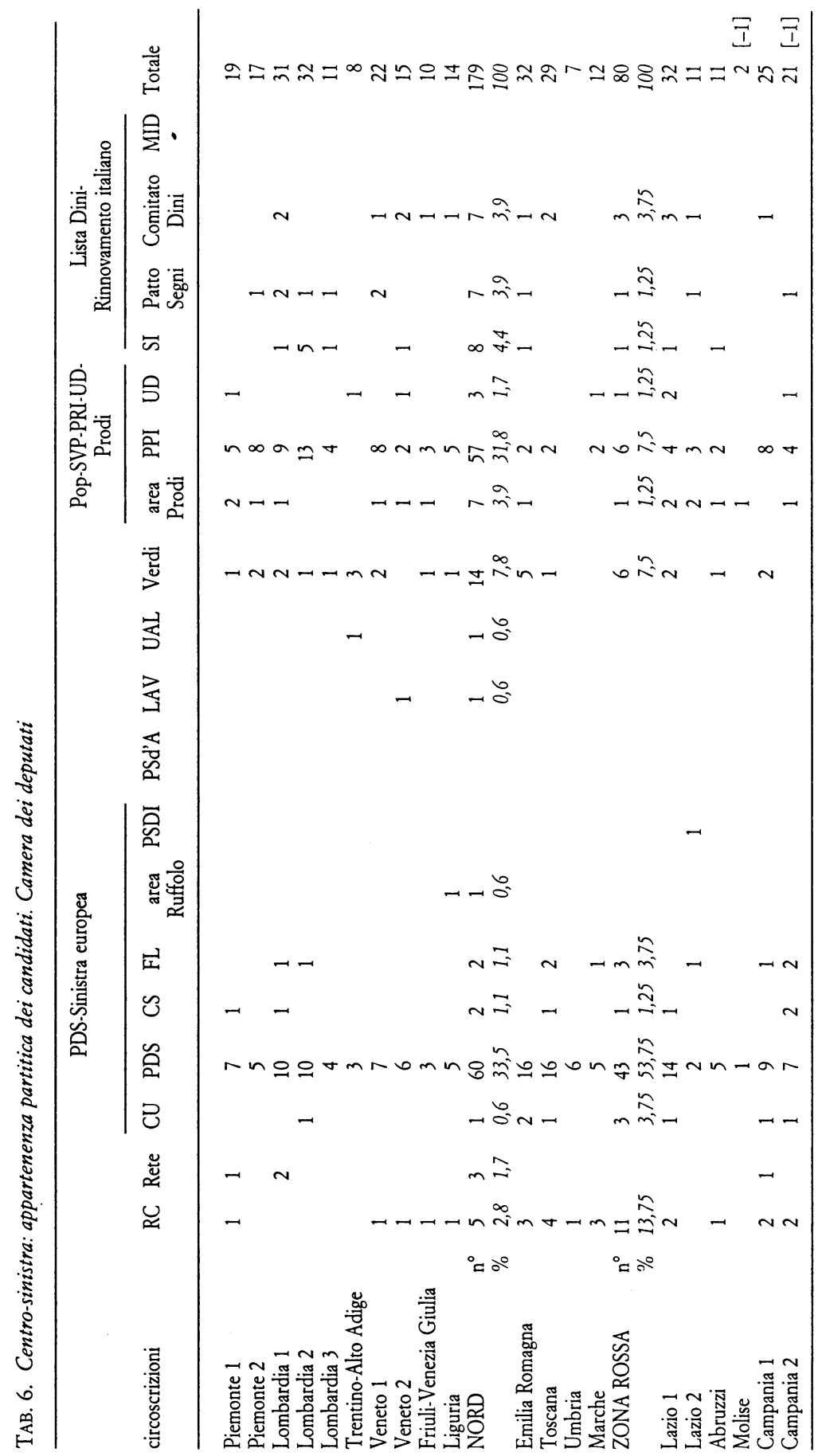




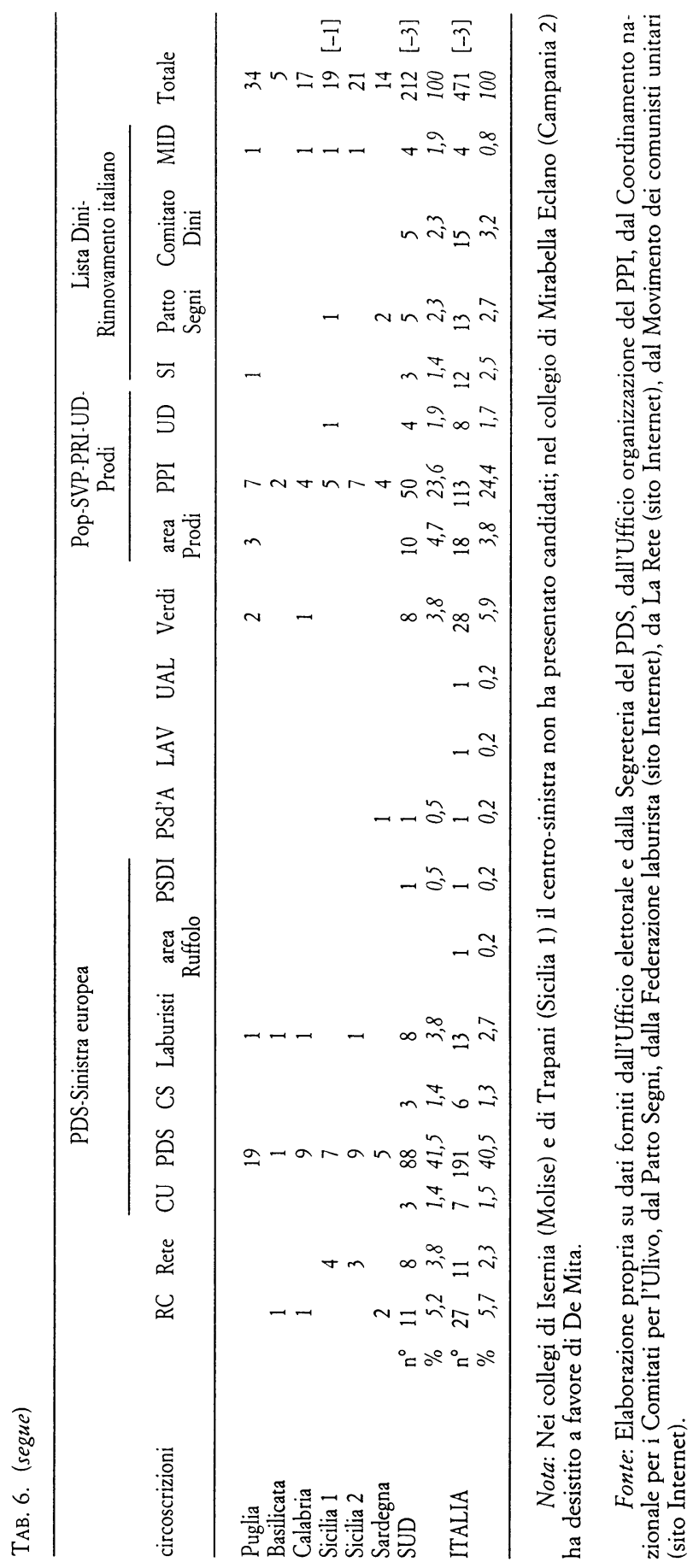




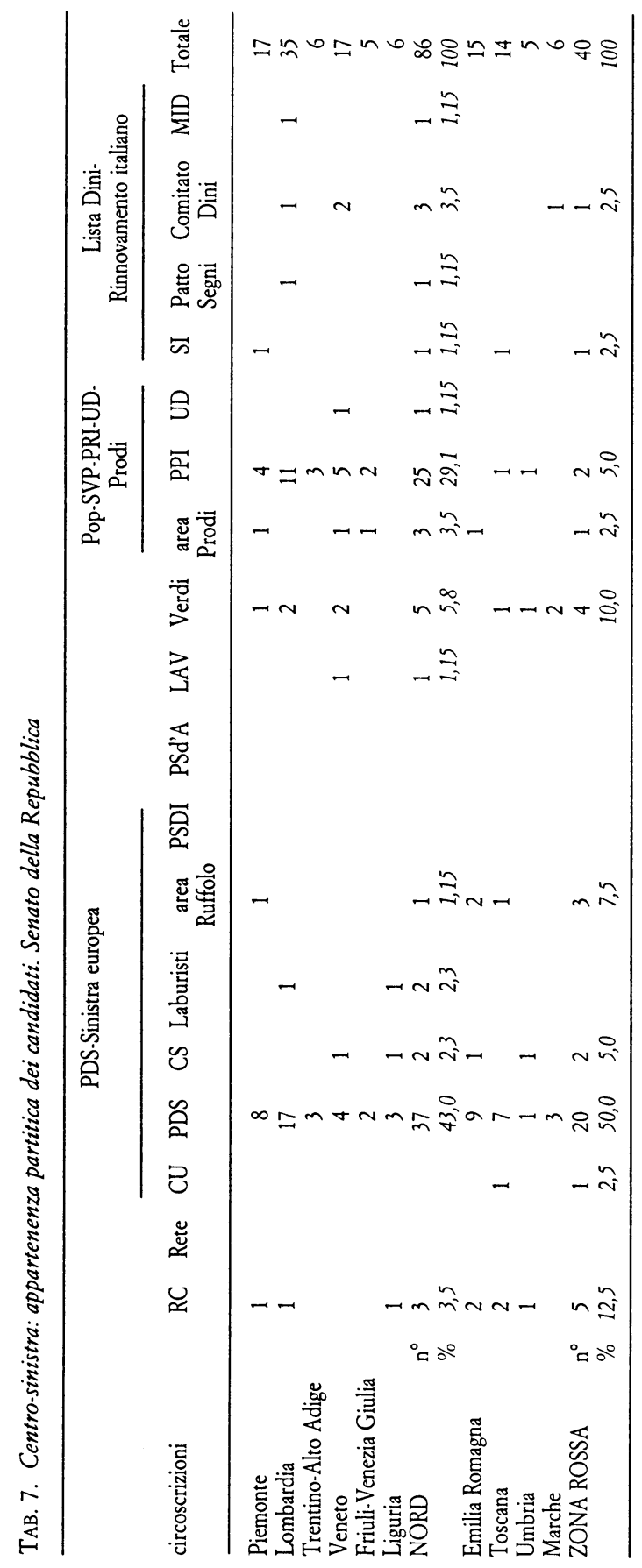




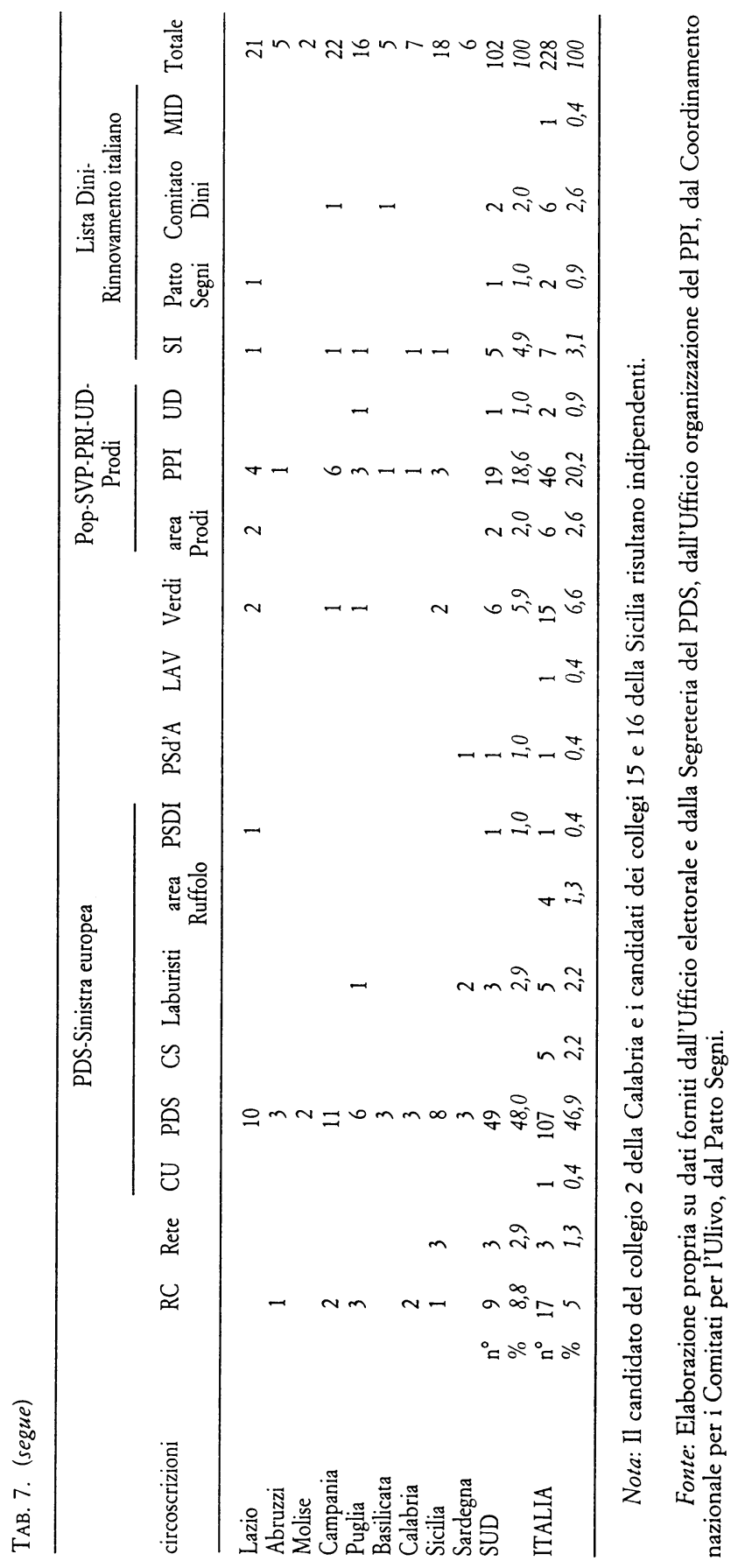


favore la bilancia della contesa fra i due centri (al termine delle trattative, a Rinnovamento italiano andranno infatti un po' meno di un quarto delle candidature assegnate al centro, con una distribuzione tra le componenti del cartello che assicura un certo vantaggio agli uomini di Dini, una presenza grosso modo paritaria per i pattisti di Segni e i Socialisti italiani e un modesto riconoscimento al Mid di Berlinguer), il Ppi si assicura con estrema facilità una posizione dominante nei confronti dei propri alleati di lista, concedendo a Prodi e ai laici di Maccanico poco più di trenta collegi complessivi (nel 1994, Alleanza democratica - che costituisce per i «cespugli» laici federati da Maccanico un termine di paragone plausibile - contava su 70 collegi, 50 alla Camera e 20 al Senato).

L'andamento della trattativa sui collegi, e i dati delle tabelle 6 e 7 che ne costituiscono il punto d'arrivo, individuano dunque nelle tre componenti coalizionali a più solida strutturazione partitica - Rc, il Pds e il Ppi - i protagonisti principali dell'alleanza di centro-sinistra. Le risorse di professionalità politica di cui tali attori dispongono vengono peraltro spese per scopi divergenti. Rifondazione - lottando con successo per il mantenimento (almeno «in entrata») dei propri «diritti acquisiti» - e il Partito popolare - riuscendo a spuntare, grazie a una sperimentata capacità di gestione, una quota di collegi ragguardevole (in particolare nelle regioni del Nord, dove detiene un peso di poco inferiore al Pds) - lavorano soprattutto in una prospettiva di autoalimentazione. Il Pds - investendo più di altri nella costruzione della coalizione e caricandosi degli oneri della conduzione della coalizione - spende invece una parte non trascurabile delle proprie risorse nell'innovazione, puntando prioritariamente al successo elettorale dello schieramento e assumendo principalmente su di sé i rischi e i costi di una tale scelta. In tal senso, il Partito democratico della sinistra si propone come coalition maker, assumendo un ruolo pivotale in quanto attore decisivo nei molti snodi dell'alleanza (l'accordo di desistenza con Rc, il tavolo dell'Ulivo, gli stessi rapporti tra le componenti centriste) e allestendo una campagna elettorale incentrata più sulla coalizione - e sull'obiettivo del successo della coalizione - che non sull'affermazione della propria identità partitica ${ }^{45}$.

45 La rinuncia a presentare il proprio simbolo nel maggioritario e a considerare la massimizzazione del voto proporzionale come obiettivo prioritario della campagna elettorale sono elementi che sembrano andare in questa direzione. 


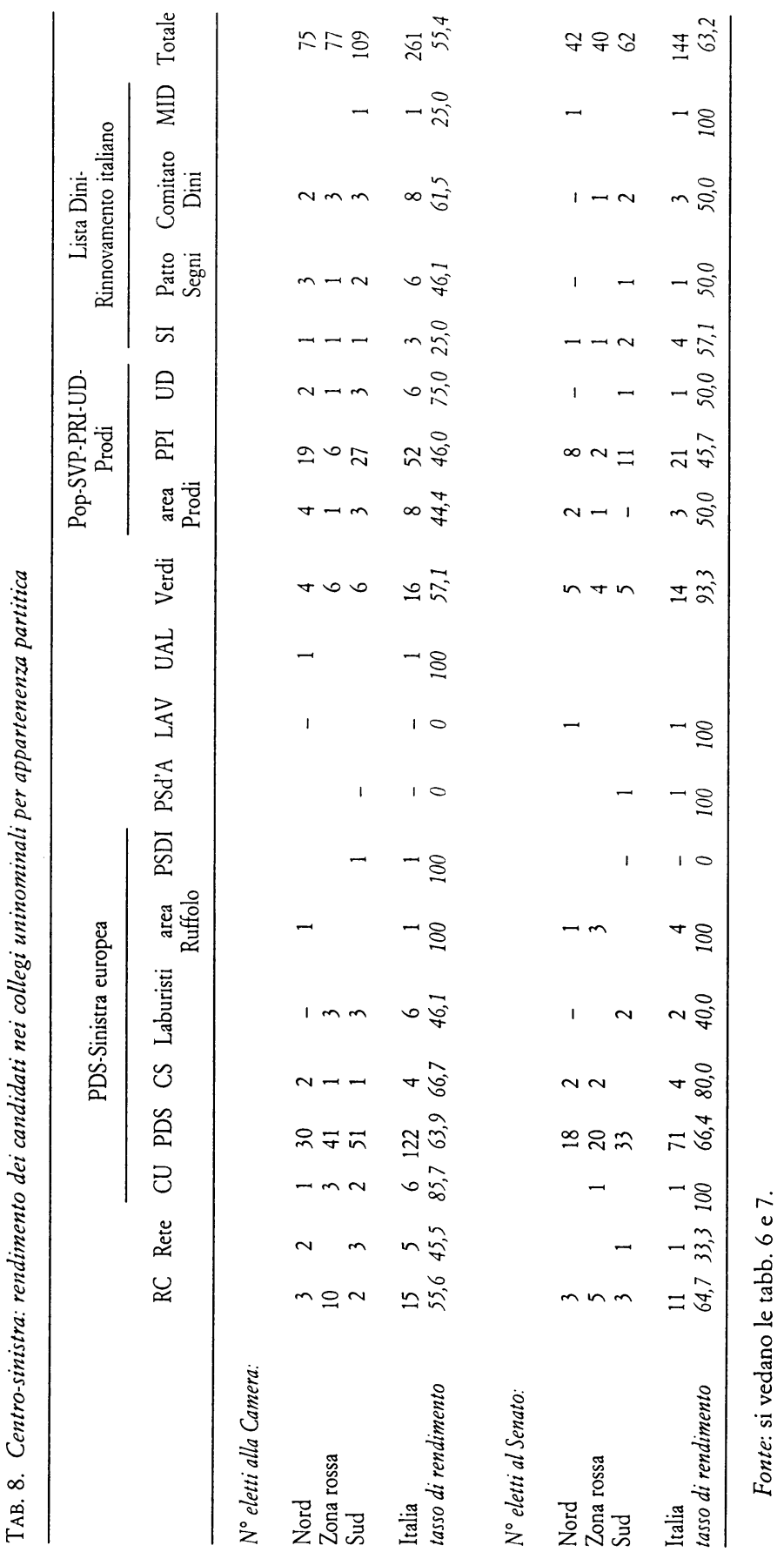


Il ruolo del Pds viene premiato non solo con il conseguimento dell'obiettivo, ma anche in termini di rendimento relativo all'interno della coalizione. Come si può osservare dalle percentuali riportate nella tabella 8 , mentre il rendimento dei candidati resta, nel caso del Ppi, al di sotto della media di schieramento e si mantiene, nel caso di Rc, sui livelli medi, i candidati pidiessini, con un tasso di successo nei collegi uninominali pari al $65 \%$, ottengono un risultato assai migliore di quello della coalizione (il Pds, che nel 1994 aveva conquistato 118 collegi complessivi, ottiene questa volta 193 seggi maggioritari). Il risultato appare positivo anche per le sigle raccolte nella Sinistra europea - per i comunisti unitari e i cristiano-sociali più che per i laburisti -, nonché per gli uomini di Dini, che fanno meglio dei loro alleati di cartello.

L'esperienza del 1994, la disponibilità dei risultati del voto regionale del 1995, le risorse e l'attenzione profuse allo scopo hanno contribuito a imporre, come elemento della trattativa infracoalizionale sui collegi e come ingrediente della strategia elettorale delle singole alleanze, un'importante variabile aggiuntiva: la valutazione della qualità dei collegi uninominali. In una competizione maggioritaria, come è noto, tale variabile assume una rilevanza decisiva. Dalla qualità dei collegi, ad esempio, dipende in larga parte - nella misura in cui si tratti di collegi «sicuri» $o$, al contrario, di collegi «persi in partenza» - il vero valore delle spoglie conquistate al tavolo coalizionale. Il numero dei collegi nei quali l'esito appare più incerto - i collegi cosiddetti «marginali» - e la capacità di aggiudicarseli determinano tipicamente, d'altro canto, l'esito complessivo di una competizione maggioritaria.

Già nel 1994, beninteso, le considerazioni legate alla qualità dei collegi avevano rappresentato un aspetto della trattativa. La scarsa familiarità degli attori con le nuove regole del gioco elettorale e la difficoltà di stimare l'affidabilità di collegi nuovi di zecca in una fase di turbolenza elettorale avevano tuttavia ridotto, e reso comunque poco sistematica, la possibilità di impiego di tali stime. Giunti alla seconda applicazione della nuova legge elettorale, il rating dei collegi è diventato uno strumento di uso più ampio. Come si vedrà, tale issue ha suscitato investimenti di risorse politiche, organizzative e materiali differenziate, attraverso un diseguale ricorso a competenze specifiche e a iniziative ad boc. Per poter definire una mappa dei collegi secondo il loro 
diverso grado di affidabilità elettorale, gli attori del gioco coalizionale si sono basati, in primo luogo, sull'impiego di dati elettorali retrospettivi ${ }^{46}$, integrati, a seconda dei casi, da dati di survey, da un'analisi fine di specifiche aree, dal monitoraggio dei collegi ritenuti marginali.

Le tabelle che seguono riportano, con riferimento alla $\mathrm{Ca}$ mera dei deputati ${ }^{47}$, una serie di dati relativi all'affidabilità presunta dei collegi uninominali ${ }^{48}$. È possibile ricavarne, da un lato (tabb. 9 e 10), un quadro delle aspettative nutrite dalle due alleanze rispetto al possibile esito della competizione maggioritaria e, retrospettivamente, una valutazione in merito alla capacità previsionale di ciascuna di esse; dall'altro (tabb. 11 e 12 per il centro-destra; tabb. 13 e 14 per il centro-sinistra), una valutazione delle spoglie attribuite a ciascuna componente che getta nuova luce sulle relazioni infracoalizionali, sull'abilità negoziale di ciascuna componente e sul suo effettivo rendimento.

I dati in questione hanno origine diversa e sono stati utilizzati dalle due coalizioni in modi distinti. I valori riportati nella tabella 9 rispecchiano solo in parte le effettive valutazioni degli attori ${ }^{49}$, essendo tratti da uno scenario elaborato dalla

46 La fonte principale - e, per la maggior parte degli attori, l'unico strumento utilizzato nella trattativa sui collegi - è stata, in proposito, la riaggregazione del voto regionale in base ai collegi uninominali di Camera e Senato predisposta dal Servizio elettorale del Ministero degli Interni come «dato retrospettivo» in vista delle politiche.

$47 \mathrm{Da}$ quel che risulta dalle fonti, entrambe le coalizioni hanno lavorato essenzialmente sui collegi della Camera e solo per inferenza sui collegi senatoriali. Questo modo di procedere, pienamente giustificato per il centro-sinistra dal fatto che la coalizione sembra godere nei collegi senatoriali di vita più facile, appare del tutto incomprensibile nel caso del centro-destra che invece nella competizione per la camera alta trova le maggiori difficoltà (Bartolini e D'Alimonte 1995b).

48 Ricostruire la mappa dell'affidabilità elettorale dei collegi uninominali alla vigilia del voto non è stata impresa facile, per la difficoltà di reperire le fonti adeguate (nel caso del centro-destra: si veda la nota seguente) e per l'iniziale indisponibilità del centro-sinistra a rendere noti tali dati, in particolare quelli relativi all'identificazione dei collegi marginali. Desidero ringraziare per la disponibilità e l'aiuto accordati Gianni Cùperlo, Antonio Deparolis, Altero Matteoli, Giampaolo Parenti, Lapo Pistelli, Antonella Rossi, Mario Tassone, Mauro Zani. Ringrazio inoltre Mauro Calise con cui ho discusso questo aspetto del lavoro.

49 An e il Cdu hanno reso cortesemente disponibile il documento siglato dai leader del Polo al termine delle trattative, in cui è riportato l'elenco definitivo dei candidati e l'indicazione della qualità del collegio (secondo tre fasce di collegi: «A», sicuri; «B», di incerta attribuzione; «C», dati per persi), ma esso risulta identicamente e inspiegabilmente incompleto, lasciando in bianco le indicazioni relative a Piemonte, Friuli-Venezia Giulia, Liguria, parte della Puglia e Sardegna. Oltre ai dati della Diakron riportati nelle 
Diakron $^{50}$ su commissione di Forza Italia e messo poi a disposizione degli altri partiti del Polo all'inizio del 1996. Tale scenario era costruito su una soglia di marginalità pari a 10.000 voti di vantaggio/svantaggio di una coalizione sull'altra, definendo una fascia di collegi di attribuzione incerta decisamente troppo estesa ${ }^{51}$; per ovviare a questo inconveniente e per rendere i dati della Diakron comparabili con la mappa d'affidabilità dei collegi elaborata dall'Ulivo, nella tabella 9 si è adottata una soglia di marginalità pari a 5.000 voti. I valori riportati nella tabella 10 sono invece di diretta provenienza partitica. Si tratta di dati elaborati dai due principali partiti della coalizione a partire dai risultati delle elezioni regionali del 1995, integrati e aggiornati da stime (partitiche) locali e, nel caso del $\mathrm{Pds}$, da uno studio di aree privilegiate (condotto attraverso surveys affidate alla $\mathrm{Swg}$ ) che ha consentito di tenere sotto osservazione per circa un anno un certo numero di collegi marginali. La fonte ha costituito, pertanto, tanto uno strumento d'orientamento per l'intero schieramento, quanto un'arma negoziale spesa al tavolo dell'Ulivo (con gli opportuni adatta-

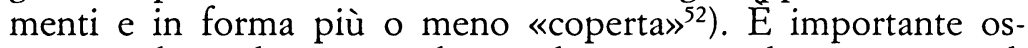
servare che $i$ due partiti hanno lavorato su di un criterio di marginalità pari a tre-quattro punti percentuali di vantaggio/ svantaggio di una coalizione sull'altra, definendo così un insieme di collegi marginali sufficientemente ristretto e attendibile.

Cosa si ricava, dunque, dal rating dei collegi uninominali della Camera definito dalle due coalizioni alla vigilia del voto? Dal confronto tra le tabelle 9 (centro-destra) e 10 (centro-sinistra) - in cui si presenta una mappa dei collegi articolata in

tabelle 9,11 e 12, le componenti del Polo hanno fondato le loro valutazioni qualitative dei collegi sull'analisi dei dati elettorali retrospettivi e su criteri di opportunità politica.

$50 \mathrm{Si}$ tratta di stime ricavate sulla base di un campione di 21.000 interviste telefoniche realizzate tra il settembre 1995 e il gennaio 1996 e delle risposte a una domanda sulle intenzioni di voto nella competizione proporzionale.

51 Una differenza di 10.000 voti corrisponde a circa dieci punti percentuali di distanza - che diventano nelle aree a minor tasso di partecipazione elettorale anche più di quindici: un criterio di marginalità davvero eccessivo! Sulla base di tale criterio, la Diakron considerava marginali poco meno della metà dei collegi (133 con il Polo in vantaggio, 97 con il Polo in svantaggio), mentre i collegi sicuri si riducevano a 67 (21 al Nord e 46 al Sud) e i collegi persi in partenza diventavano 177.

$52 \mathrm{Nel}$ corso della trattativa sui collegi, il Pds ha teso, ad esempio, ad estendere la fascia dei collegi ritenuti marginali e a restringere invece la fascia dei collegi ritenuti sicuri, in modo da indurre gli alleati ad accettare candidature anche in collegi marginali e contenere, al tempo stesso, l'assalto ai collegi (sicuri) delle regioni rosse. 
quattro classi: i collegi «ritenuti sicuri», i collegi «ritenuti marginali» in positivo o in negativo, $\mathrm{i}$ collegi «ritenuti persi in partenza» - emergono, anzitutto, le diverse aspettative nutrite dalle due coalizioni rispetto al possibile risultato della competizione maggioritaria. Il centro-destra si muoveva in un orizzonte entro cui la sconfitta si presentava come l'esito più probabile. Secondo lo scenario della Diakron, ben 218 collegi su 474 dovevano considerarsi per il Polo collegi senza speranza. Su questo dato incidevano pesantemente le circoscrizioni del Nord, dove, dato ancora per possibile l'accordo fra Lega e Ulivo, il numero dei collegi ritenuti persi in partenza superava addirittura il $60 \%$ del totale (vi rientravano per intero i collegi di Lombardia 2, Lombardia 3 e delle due circoscrizioni venete). Di poco superiore a un quarto del totale, invece, era la quota di collegi considerati sicuri (più dei due terzi dei quali concentrati al Sud), mentre quasi la metà dei collegi ritenuti marginali era stimata con il Polo in svantaggio nei confronti della coalizione avversaria. Assai diversa da quella appena esaminata risultava, invece, la distribuzione dei collegi uninominali secondo classi di affidabilità operata dal Pds e dal Ppi. In questo caso, il quadro si presentava sostanzialmente incerto, pur se con una leggera preponderanza della coalizione Ulivo-Rc. Alla perfetta simmetria tra collegi dati per acquisiti e collegi, invece, ritenuti inaccessibili (le due classi contenevano entrambe 191 collegi), corrispondeva infatti una ripartizione dei collegi marginali che nei due terzi dei casi accreditava il centro-sinistra di un leggero vantaggio. A livello di aree macroregionali, le previsioni dei due maggiori partiti dell'Ulivo stimavano il Polo in vantaggio al Nord (oltre la metà dei collegi settentrionali era data per persa) e si discostavano sensibilmente dalle previsioni della Diakron anche nel caso dei collegi del Mezzogiorno (questa volta a proprio favore: Pds e Ppi davano 70 collegi del Sud sicuri per l'Ulivo-Rc, mentre la Diakron stimava in $27 \mathrm{i}$ collegi del Sud persi in partenza dal centro-destra).

Quando dalle previsioni delle due coalizioni si passa a considerare il rendimento effettivamente registrato in ciascuna classe di collegi - anch'esso riportato nelle tabelle 9 e 10 - tre aspetti richiamano principalmente l'attenzione. Il primo è relativo all'accuratezza della previsione. La mappa dei collegi che il centro-sinistra aveva tra le mani alla vigilia del voto - su cui la coalizione, e in particolare il Pds, imposta la propria strategia elettorale - si rivela assai attendibile. Il tasso di rendimento se- 


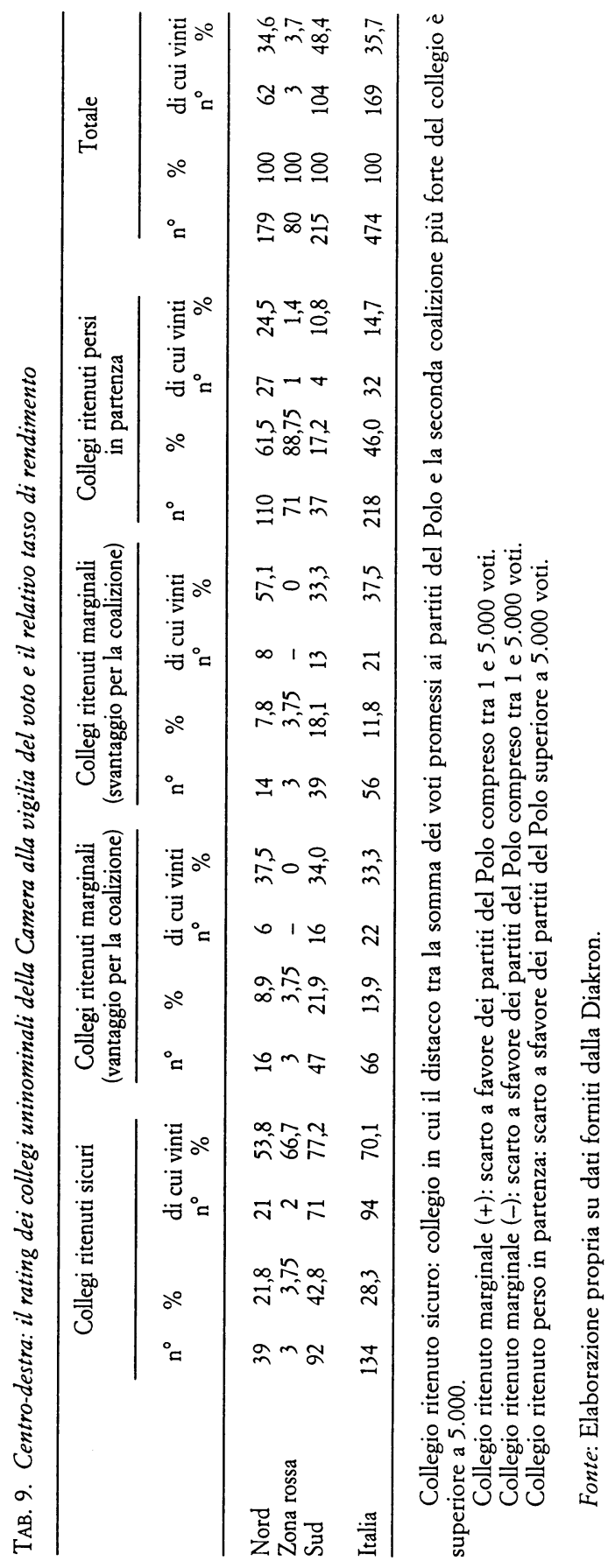




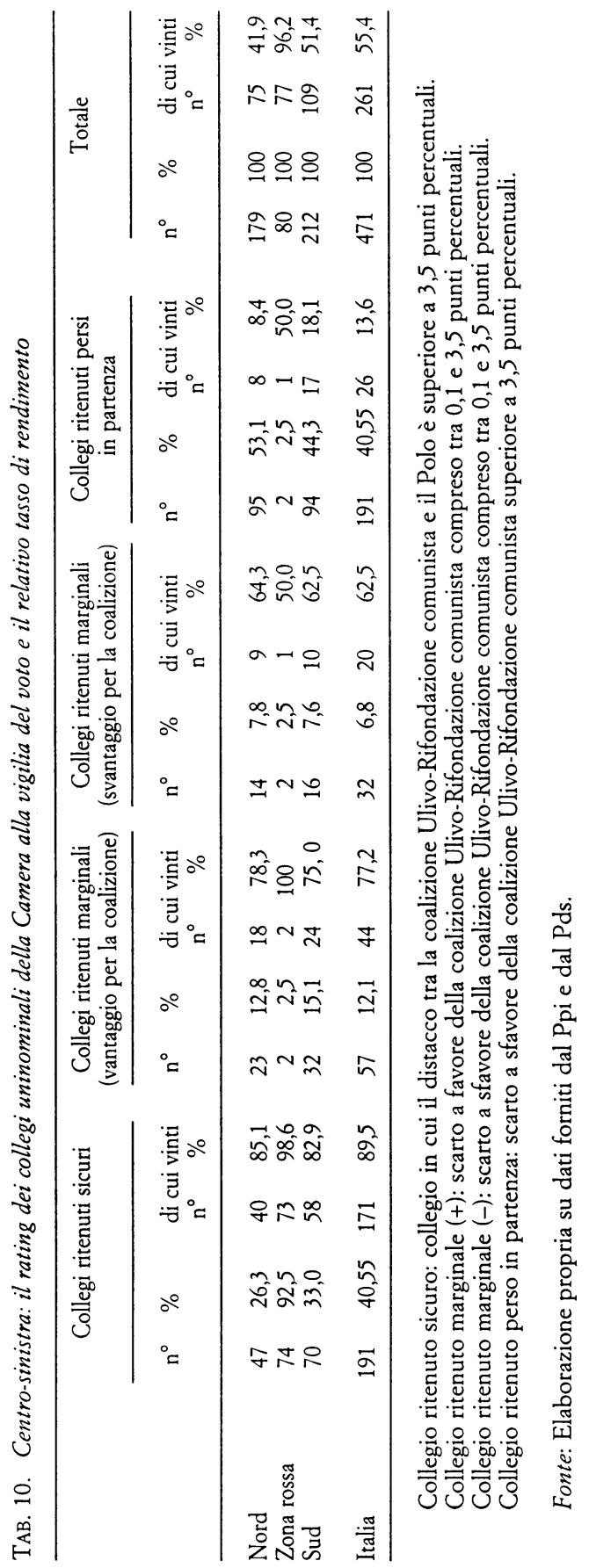


gue un andamento lineare $\mathrm{r}^{53}$ - a differenza di quanto avviene nel caso dello scenario della Diakron: nei collegi ipotizzati come marginali in svantaggio, il Polo vi esibisce risultati migliori rispetto ai collegi reputati marginali ma con la coalizione in vantaggio; nel Nord, nei collegi ipotizzati come marginali in svantaggio, ottiene un rendimento addirittura superiore a quello conseguito nei collegi ritenuti sicuri - e assume livelli congrui (supera l' $80 \%$ nei collegi ritenuti sicuri, si mantiene al di sotto del $20 \%$ nei collegi dati per persi). In secondo luogo, l'esito della competizione nei collegi ritenuti marginali appare decisivo - il centro-sinistra, come si legge nella tabella 10, fa propri tali collegi in più del $70 \%$ dei casi (con un rendimento che risulta particolarmente brillante nei collegi marginali del Nord, dove la coalizione trae evidente vantaggio dall'andamento del voto ai candidati della Lega); il Polo, come si osserva nella tabella 9, in poco più del $35 \%$ - e lo stesso può dirsi del risultato ottenuto nei collegi sicuri (il Polo vi registra un tasso di successo dell' $87 \%$, il centro-sinistra quasi del $90 \%$ ma su una base tre volte superiore). A livello macroregionale, infine, emerge con evidenza la meridionalizzazione del profilo del Polo (si collocano al Sud quasi il $70 \%$ dei collegi ritenuti sicuri dalla coalizione e oltre il $70 \%$ di quelli marginali col centro-destra in leggero vantaggio), soprattutto quando si osservano i tassi di rendimento (si trovano al Sud, che conta il $45 \%$ dei collegi, oltre il $75 \%$ dei collegi considerati sicuri, e il $67 \%$ dei collegi marginali effettivamente conquistati). Ad esso corrisponde, nel caso del centro-sinistra, una più equilibrata distribuzione qualitativa dei collegi tra Nord e Sud.

L'incrocio tra i dati relativi al rating coalizionale dei collegi e l'appartenenza partitica dei candidati e degli eletti consente di svolgere alcune considerazioni sui rapporti tra le componenti partitiche delle alleanze e sulle prestazioni dei loro candidati. A tal fine, per entrambe le alleanze, si sono ricostruiti la distribuzione qualitativa del pacchetto di candidature attribuito a ciascun partner coalizionale e il rispettivo rendimento per classe di collegio e area macroregionale.

Nel polo di centro-destra (tabb. 11 e 12), Alleanza naziona-

53 Per l'esiguità delle unità presenti in tre delle quattro classi, il caso della Zona rossa - in cui il rendimento della coalizione è più elevato nei collegi marginali (con vantaggio per la coalizione) che non nei collegi sicuri, mentre nei collegi persi in partenza è uguale a quello dei collegi marginali (con svantaggio per la coalizione) - non fa testo. 
TAB. 11. Distribuzione dei collegi tra le componenti partitiche del Polo per classe di collegi

Collegi ritenuti Collegi ritenuti Collegi ritenuti Collegi ritenuti Totale sicuri marginali $(+)$ marginali $(-)$ persi in partenza

\begin{tabular}{lcccccc}
\hline \multirow{2}{*}{ AN } & $\mathrm{n}^{\circ}$ & 56 & 29 & 15 & 62 & 162 \\
& $\%$ & 34,6 & 17,9 & 9,2 & 38,3 & 100 \\
Forza Italia & $\mathrm{n}^{\circ}$ & 59 & 28 & 30 & 104 & 221 \\
& $\%$ & 26,7 & 12,7 & 13,6 & 47,0 & 100 \\
FLD & $\mathrm{n}^{\circ}$ & 1 & 1 & 2 & 6 & 10 \\
& $\%$ & 10,0 & 10,0 & 20,0 & 60,0 & 100 \\
CCD & $\mathrm{n}^{\circ}$ & 13 & 3 & 4 & 21 & 41 \\
& $\%$ & 31,7 & 7,3 & 9,8 & 51,2 & 100 \\
CDU & $\mathrm{n}^{\circ}$ & 5 & 5 & 5 & 25 & 40 \\
& $\%$ & 12,5 & 12,5 & 12,5 & 62,5 & 100 \\
Totale & $\mathrm{n}^{\circ}$ & 134 & 66 & 56 & 218 & 474 \\
& $\%$ & 28,3 & 13,9 & 11,8 & 46,0 & 100 \\
\hline
\end{tabular}

Fonte: Si vedano le tabelle 3 e 9.

le conquista nella trattativa sui collegi posizioni di gran lunga migliori di quelle dei propri alleati, esibendo la quota più cospicua di collegi ritenuti sicuri e la quota più modesta di collegi ritenuti persi in partenza (vi correvano, rispettivamente, il $35 \%$ e il $38 \%$ dei candidati di An). La posizione del partito di Fini si presenta particolarmente solida al Sud, dove detiene la metà dei collegi sicuri e il $40 \%$ di quelli marginali, e, in termini di rendimento, soprattutto nei collegi sicuri, dove elegge il $75 \%$ dei suoi candidati contro una media di schieramento del $70 \%$. Nel caso di Forza Italia, invece, la distribuzione dei collegi in classi di affidabilità elettorale si attesta attorno ai valori medi, leggermente al di sotto della media quando si tratta di collegi dati per sicuri o ritenuti marginali con il Polo in vantaggio, leggermente al di sopra nei collegi dati per persi o ritenuti marginali con il Polo in svantaggio. In termini territoriali e di rendimento, tre aspetti risultano meritevoli di attenzione: Forza Italia riesce a ottenere per sé i due terzi dei collegi sicuri del Nord, ma vi registra un rendimento del $58 \%$, risultato assai modesto in un'area di presunti «collegi fortezza» (e inferiore al corrispettivo rendimento di An, che nel Nord conquista sei dei nove collegi sicuri attribuitile); ottiene nei collegi sicuri del Sud un rendimento che sfiora invece $1 ' 80 \%$ (di poco superiore al rendimento conseguito, su una base di collegi assai più ampia, da An); registra il suo miglior risultato relativo, commisurato cioè 


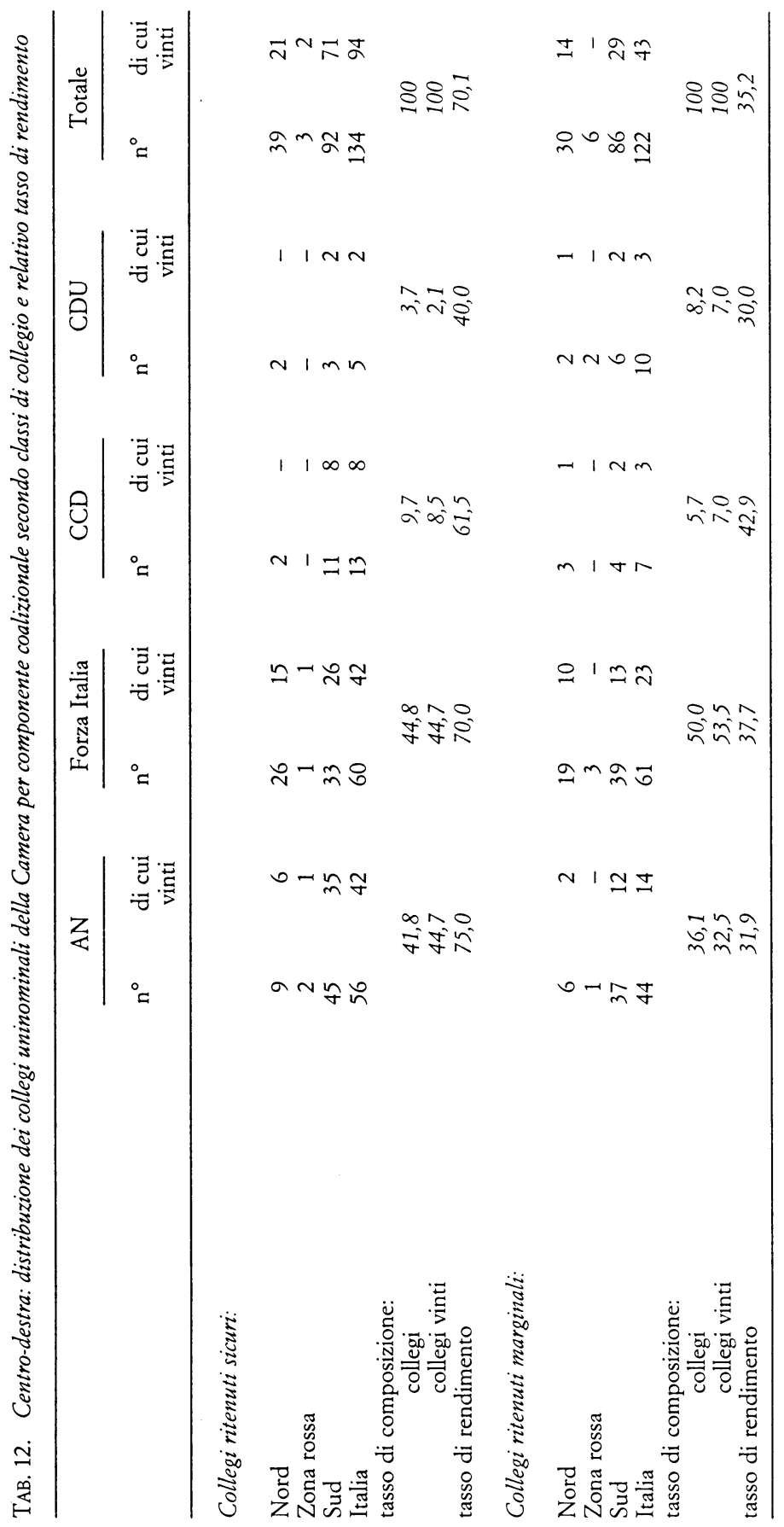




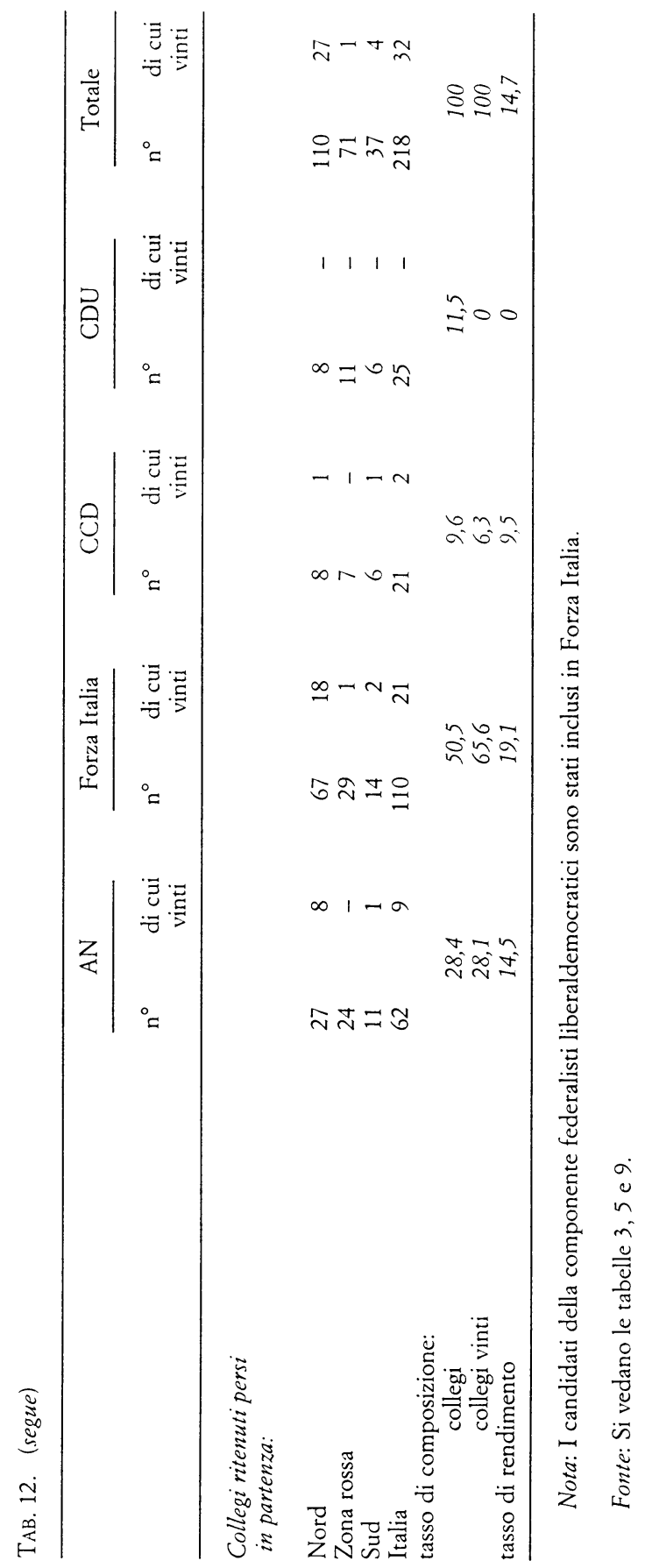


all'andamento delle altre componenti dell'alleanza, nei collegi marginali, con un rendimento (non proprio brillante) del $37,7 \%$, e va meglio delle altre componenti anche nei collegi ritenuti persi in partenza. Le due tabelle evidenziano, infine, la debolezza del Ccd e del Cdu all'interno della coalizione. Se il Ccd, grazie ai collegi sicuri spuntati nel Lazio, in Campania e in Sicilia, vanta una quota di collegi sicuri superiore alla media, le due componenti ex democristiane appaiono infatti fortemente sovrarappresentate unicamente nella classe dei collegi ritenuti persi in partenza e presentano valori sistematicamente inferiori ai valori medi anche in termini di rendimento.

$\mathrm{Nel}$ caso dello schieramento di centro-sinistra, anche la distribuzione dei collegi in classi di affidabilità elettorale (riportata nella tab. 13) necessita di un esame a più livelli. Un primo aspetto da considerare è il rapporto tra sinistra e centro. La tabella mostra a questo proposito come la sinistra si sia assicurata la larga maggioranza dei collegi sicuri (134 contro 52), lasciando al centro il primato nella classe di collegi ritenuti persi in partenza e una leggera prevalenza nella fascia dei collegi marginali. La squilibrata ripartizione dei collegi ritenuti sicuri deve molto a Rc, che, a saldo dell'accordo di desistenza, ottiene 23 collegi di prima fascia su 27 , e, inoltre, alla capacità negoziale del Pds, che si assicura 100 collegi sicuri su 191, pari a un'incidenza percentuale seconda soltanto a Rifondazione (oltre che ai Comunisti unitari: quattro collegi sicuri su sette). Un secondo aspetto meritevole di attenzione è il rapporto tra le forze di centro. I Verdi, facendo valere la loro seniority di schieramento e il criterio della riconferma degli uscenti (i collegi, non necessariamente le persone), si ritagliano la distribuzione più vantaggiosa. Anche i popolari non escono male dalla partita, soprattutto nel loro confronto a distanza con il centro di Dini (pur se «appesantito» da 81 collegi ritenuti persi in partenza, il pacchetto di collegi assegnato al cartello Popolari per Prodi conta su circa un quarto di collegi reputati sicuri; Rinnovamento, invece, non va al di là di 8 collegi di prima fascia su 44 e vede una metà dei propri collegi ricadere nella categoria di minor qualità, nonostante conti una quota di collegi marginali superiore alla media). Un terzo aspetto da considerare è, infine, quello della ripartizione qualitativa dei collegi all'interno dei cartelli proporzionali. Il Pds, ad esempio, sembra resistere senza eccessive difficoltà all'«assalto» dei «cespugli» della Sinistra europea - e, probabilmente, a sacrificare un minor numero di posizioni 
TAB. 13. Distribuzione dei collegi tra le componenti partitiche del centro-sinistra per classe di collegi

\begin{tabular}{|c|c|c|c|c|c|c|}
\hline & & $\begin{array}{l}\text { llegi ritenuti } \\
\text { sicuri }\end{array}$ & $\begin{array}{c}\text { Collegi ritenuti } \\
\text { marginali }(+)\end{array}$ & $\begin{array}{c}\text { Collegi ritenuti } \\
\text { marginali }(-)\end{array}$ & $\begin{array}{l}\text { Collegi ritenuti } \\
\text { persi in partenza }\end{array}$ & Totale \\
\hline \multirow[t]{2}{*}{ RC } & $\mathrm{n}^{\circ}$ & 23 & & 2 & 2 & 27 \\
\hline & $\%$ & 85,2 & & 7,4 & 7,4 & 100 \\
\hline \multirow{2}{*}{$\mathrm{CU}$} & $\mathrm{n}^{\circ}$ & 4 & 1 & 1 & 1 & 7 \\
\hline & $\%$ & 57,1 & 14,3 & 14,3 & 14,3 & 100 \\
\hline \multirow{2}{*}{ PDS } & $\mathrm{n}^{\circ}$ & 100 & 22 & 10 & 59 & 191 \\
\hline & $\%$ & 52,4 & 11,5 & 5,2 & 30,9 & 100 \\
\hline \multirow[t]{2}{*}{ CS } & $\mathrm{n}^{\circ}$ & 1 & 1 & & 4 & 6 \\
\hline & $\%$ & 16,7 & 16,7 & & 66,7 & 100 \\
\hline \multirow[t]{2}{*}{ Laburisti } & $\mathrm{n}^{\circ}$ & 6 & 1 & & 6 & 13 \\
\hline & $\%$ & 46,15 & 7,7 & & 46,15 & 100 \\
\hline area Ruffolo & $\begin{array}{l}\mathrm{n}^{\circ} \\
\%\end{array}$ & $\begin{array}{r}1 \\
100\end{array}$ & & & & $\begin{array}{r}1 \\
100\end{array}$ \\
\hline \multirow[t]{2}{*}{ PSDI } & $\mathrm{n}^{\circ}$ & & 1 & & & 1 \\
\hline & $\%$ & & 100 & & & 100 \\
\hline \multirow[t]{2}{*}{ PDS-SE } & $\mathrm{n}^{\circ}$ & 111 & 25 & 11 & 70 & 217 \\
\hline & $\%$ & 51,1 & 11,5 & 5,1 & 32,2 & 100 \\
\hline \multirow{2}{*}{ Verdi } & $\mathrm{n}^{\circ}$ & 10 & 6 & 1 & 11 & 28 \\
\hline & $\%$ & 35,7 & 21,4 & 3,6 & 39,3 & 100 \\
\hline \multirow[t]{2}{*}{ area Prodi } & $n^{\circ}$ & 3 & 3 & 1 & 11 & 18 \\
\hline & $\%$ & 16,7 & 16,7 & 5,5 & 61,1 & 100 \\
\hline \multirow{2}{*}{ PPI } & $\mathrm{n}^{\circ}$ & 28 & 12 & 5 & 68 & 113 \\
\hline & $\%$ & 24,8 & 10,6 & 4,4 & 60,2 & 100 \\
\hline \multirow{2}{*}{ UD } & $\mathrm{n}^{\circ}$ & 3 & 2 & 1 & 2 & 8 \\
\hline & $\%$ & 37,5 & 25,0 & 12,5 & 25,0 & 100 \\
\hline \multirow{2}{*}{$\begin{array}{l}\text { Pop.-UD- } \\
\text { Prodi }\end{array}$} & $n^{\circ}$ & 34 & 17 & 7 & 81 & 139 \\
\hline & $\%$ & 24,5 & 12,2 & 5,0 & 58,3 & 100 \\
\hline \multirow[t]{2}{*}{ SI } & $\mathrm{n}^{\circ}$ & 2 & 1 & 2 & 7 & 12 \\
\hline & $\%$ & 16,7 & 8,3 & 16,7 & 58,3 & 100 \\
\hline Patto Segni & $n^{\circ}$ & 3 & 3 & 1 & 6 & 13 \\
\hline \multicolumn{7}{|l|}{ Comitato } \\
\hline \multirow[t]{2}{*}{ Dini } & $\mathrm{n}^{\circ}$ & 2 & 3 & 4 & 6 & 15 \\
\hline & $\%$ & 13,3 & 20,0 & 26,7 & 40,0 & 100 \\
\hline \multirow[t]{2}{*}{ MID } & $\mathrm{n}^{\circ}$ & 1 & & & 3 & 4 \\
\hline & $\%$ & 25,0 & & & 75,0 & 100 \\
\hline \multirow{2}{*}{ Lista Dini } & $\mathrm{n}^{\circ}$ & 8 & 7 & 7 & 22 & 44 \\
\hline & $\%$ & 18,2 & 15,9 & 15,9 & 50,0 & 100 \\
\hline \multirow[t]{2}{*}{ Rete } & $\mathrm{n}^{\circ}$ & 4 & 1 & 2 & 4 & 11 \\
\hline & $\%$ & 36,35 & 9,1 & 18,2 & 36,35 & 100 \\
\hline PSd'A & $\mathrm{n}^{\circ}$ & & & 1 & & 1 \\
\hline \multirow[t]{2}{*}{ LAV } & $\mathrm{n}^{\circ}$ & & & $\begin{array}{r}100 \\
1\end{array}$ & & $\begin{array}{r}100 \\
1\end{array}$ \\
\hline & $\%$ & & & 100 & & 100 \\
\hline UAL & $\mathrm{n}^{\circ}$ & & & & 1 & 1 \\
\hline Totale & $\%$ & & & & 100 & 100 \\
\hline lotale & $\mathrm{n}_{0}$ & 191 & 57 & 32 & 191 & 471 \\
\hline Tot. Sinistra & $\mathrm{n}^{\circ}$ & $\begin{array}{l}40,39 \\
134\end{array}$ & 12,1 & 6,8 & 40,55 & 100 \\
\hline Tot. Centro & $\mathrm{n}^{\circ}$ & $\begin{array}{r}14 \\
52\end{array}$ & 30 & $\begin{array}{l}13 \\
15\end{array}$ & 114 & $\begin{array}{l}244 \\
211\end{array}$ \\
\hline$\%$ Sinistra & & 72,0 & 45,5 & 46,4 & 38,7 & 53,5 \\
\hline \% Cen & & 28,0 & 54,5 & 53,6 & 61,3 & 46,5 \\
\hline
\end{tabular}

Nota: Sinistra comprende i candidati di Rc e del Pds-Se; Centro i candidati dei Verdi, del Pop.-Svp-Pri-Ud-Prodi e della Lista Dini.

Fonte: Si vedano le tabelle 6 e 10. 


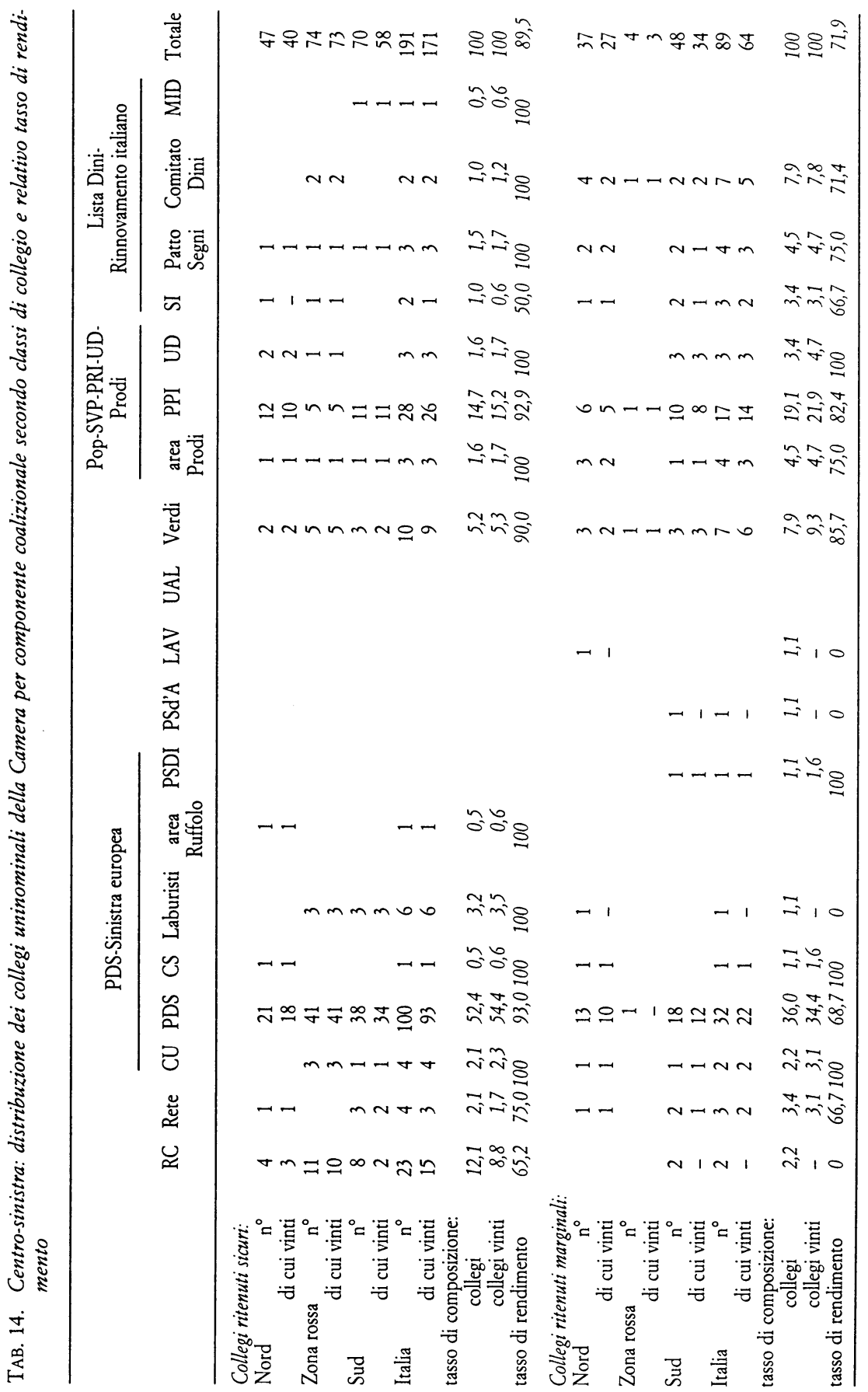




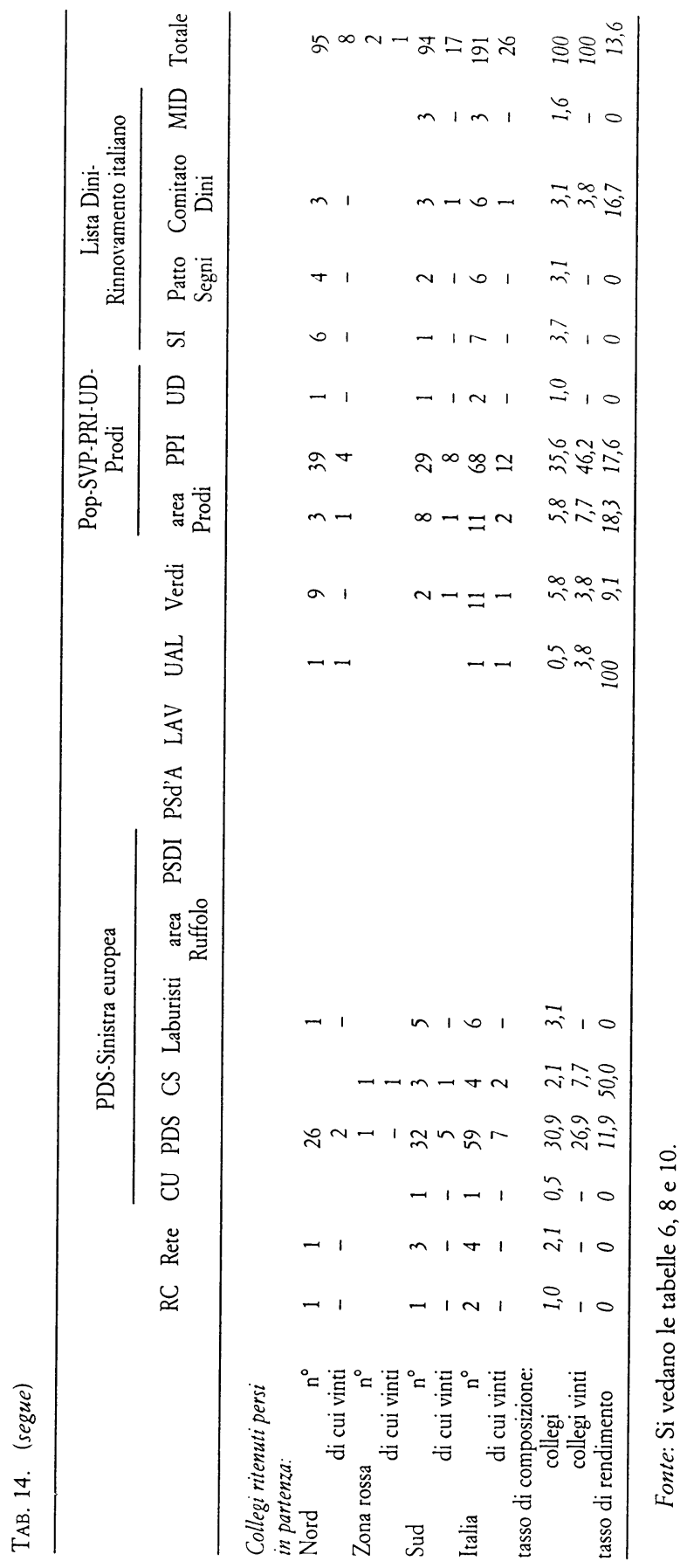


rispetto al $1994^{54}$ - imponendo anche agli alleati un criterio che contemperasse qualità e quantità dei collegi (i laburisti ne escono meglio dei comunisti unitari e, soprattutto, dei cristiano-sociali). I popolari, dal canto loro, assicurano agli sparuti rappresentanti dei «cespugli» laici collegi di qualità in cinque casi su otto, riservando per sé posizioni migliori di quelle assegnate ai candidati dell'area Prodi. Un po' meno diversificate, infine, si presentano le posizioni all'interno di Rinnovamento italiano, dove al Comitato Dini e al Patto Segni vengono assicurate, nella ripartizione interna al cartello, le spoglie che sulla carta appaiono migliori.

Le modalità distributive dei collegi secondo la loro qualità sono contraddette dai dati relativi al rendimento solo in piccola parte (lo si è già visto presentando i valori della tab. 10), ma, una volta che la valutazione delle prestazioni venga condotta a livello di famiglie di candidati e di singole componenti partitiche, in modo egualmente significativo. L'elemento più rilevante, a riguardo, è senz'altro il risultato di Rifondazione comunista. Con un esito che sembra riproporre, pur se in un diverso contesto e su scala ridotta, il fenomeno della difficile sommabilità dei voti della sinistra resosi evidente nel 1994 (Bartolini e D'Alimonte 1995b), i candidati progressisti, lo si può osservare nella tabella 14 , conquistano soltanto 15 dei 23 collegi ritenuti sicuri loro assegnati; nel Sud, in particolare, Rc si aggiudica appena due collegi sicuri su otto ${ }^{55}$. Un secondo aspetto meritevole di attenzione e speculare al precedente - poiché anch'esso riferibile, a parti inverse, all'elasticità del voto degli elettori dello schieramento (ovvero al diverso grado di trasferibilità del voto che si manifesta al variare dell'appartenenza partitica dei candidati) - è la prestazione dei candidati di centro e, in particolare, dei candidati del cartello Popolari per Prodi. Come si ricava dai dati della tabella 14 , si tratta dell'unica famiglia di candidati in grado di esibire un rendimento superiore alla media di schiera-

54 Non disponendo di dati sulla distribuzione qualitativa dei collegi relativi al 1994, lo si può inferire da quanto accade nei collegi della Zona rossa: il Pds ne deteneva 44 alla Camera e 17 al Senato (con una sola sconfitta, alla Camera) nel 1994); malgrado la maggiore estensione della coalizione, ne conta, nel 1996, 43 alla Camera e 20 al Senato (con due sconfitte, entrambe alla Camera).

$55 \mathrm{La}$ coalizione di centro-sinistra viene sconfitta in venti collegi ritenuti sicuri alla vigilia del voto. Di questi, come si ricava dalla tabella 14 , otto erano in quota $\mathrm{Rc}$, sette in quota Pds, due collegi erano stati assegnati ai popolari, uno ai Verdi e uno alla Rete. 
mento in tutte e tre le classi di collegi ${ }^{56} \mathrm{e}$, in particolare, nei collegi marginali, collegi in cui anche $\mathrm{i}$ Verdi fanno molto bene. A livello di singole componenti partitiche, in terzo luogo, Pds e Ppi confermano anche in termini di rendimento la propria supremazia sulle rispettive aree di appartenenza, mentre tra $\mathrm{i}$ «cespugli» lo spazio accordato alle diverse formazioni è in parte contraddetto dalle rispettive prestazioni (come emerge, in positivo, dal risultato dei cristiano-sociali e dei candidati dell'Unione democratica e, in negativo, dal rendimento dei laburisti, dei candidati dell'area Prodi e dei socialisti italiani).

L'operatività delle alleanze conta di almeno due altri aspetti rilevanti. Si tratta del grado di territorializzazione dei due schieramenti e delle scelte da essi operate nell'arena proporzionale.

Il primo aspetto acquista particolare rilievo dopo la riforma elettorale del 1993, poiché, contrariamente alla proporzionale, i sistemi maggioritari in collegi uninominali si trovano comunemente associati ad una selezione (anche) locale dei candidati parlamentari, nonché - per il prevalere di una concezione della rappresentanza politica come rappresentanza anzitutto territoriale - ad una caratterizzazione (anche) localistica della classe politica parlamentare.

La disponibilità di due sole prove elettorali rende per il momento prematuro, nel caso italiano, poter esprimere valutazioni a riguardo, tanto più in presenza di un sistema partitico in evoluzione (e non ancora assestato dopo lo «strappo» dei primi anni Novanta) e di alleanze che da un'elezione all'altra mutano la propria configurazione ${ }^{57}$. Esaminando le modalità di ricandidatura dei parlamentari uscenti, è possibile, tuttavia, fornire alcune informazioni su uno specifico aspetto, che può essere as-

56 I candidati Pds-Sinistra europea restano infatti al di sotto del rendimento medio coalizionale tanto nei collegi ritenuti persi in partenza, in compagnia dei Verdi, quanto nei collegi ritenuti marginali. I candidati di Rinnovamento, invece, si attestano al di sotto della media in tutte e tre le classi di collegi, allo stesso modo dei candidati di Rifondazione.

57 È plausibile considerare l'instabilità delle coalizioni elettorali alla stregua di un fattore interveniente in grado di sfavorire ipotetiche dinamiche di territorializzazione in atto. Anche per questo motivo, Mattina e Tonarelli (1996) riscontrano una modesta territorializzazione dei candidati; il quadro, tuttavia, non sembra privo di differenze a livello partitico (anche all'interno dello stesso schieramento: mentre, ad esempio, i candidati di Forza Italia sconfitti nel 1994 tendono a uscire di scena, i candidati sconfitti di An con maggior frequenza si ripresentano nello stesso collegio di due anni prima) che fanno capo al loro diverso insediamento periferico e diverso grado di istituzionalizzazione. 
sunto come condizione minima di territorializzazione: il nesso tra incumbency e collegio.

Come si ricava dalla tabella 15 , il comportamento prevalente dei parlamentari uscenti - o meglio di quegli uscenti, oltre i tre quarti del totale, che si ricandidano nello stesso ramo del parlamento e non sono quindi né provenienti da o diretti verso l'arena proporzionale, né in transito da una camera all'altra - è di presentarsi al giudizio degli elettori del collegio di provenienza. Ciò avviene con maggiore evidenza fra i parlamentari uscenti del centro-destra (80\% dei casi alla Camera; $89,4 \%$ dei casi al Senato) che non fra quelli del centro-sinistra (la scelta dello stesso collegio vale qui nel $74,6 \%$ dei casi alla Camera e nell' $86,8 \%$ dei casi al Senato) e della Lega (72,5\% alla Camera e $85,7 \%$ al Senato).

Il confronto tra rendimento degli incumbents di collegio e rendimento dei parlamentari uscenti che abbandonano il collegio di provenienza consente un passaggio ulteriore: mettere alla prova l'ipotesi che vede nel radicamento territoriale un'importante risorsa competitiva. Poiché l'ipotesi, oltre che per il radicamento dei parlamentari uscenti, vale evidentemente anche per il radicamento degli sfidanti, il test è soltanto indicativo; se ne ricavano tuttavia evidenze divergenti, non tanto tra uno schieramento e l'altro, quanto tra una camera e l'altra. Alla Camera, almeno nel caso del centro-sinistra, l'incumbency di collegio sembra costituire effettivamente un vantaggio competitivo, trovandosi associata a tassi di successo più elevati (è soprattutto il caso degli uscenti del centro-sinistra, i quali riconquistano il seggio nel $90,3 \%$ dei casi quando si presentano nel collegio di provenienza e nell' $81,3 \%$ dei casi quando cambiano collegio; per gli uscenti del centro-destra, il tasso di riconferma è invece, per gli uni e per gli altri, del 61,3\%); al Senato, al contrario, la performance dei (pochi) uscenti che cambiano collegio è superiore, per il centro-sinistra come per il centro-destra, al rendimento degli uscenti che restano legati al collegio di due anni prima. Una garanzia quasi assoluta di rielezione caratterizza invece i parlamentari che si ricandidano nell'altro ramo del Parlamento, passando dalla Camera al Senato (si tratta di 21 deputati uscenti, 14 dei quali del centro-sinistra, tutti eletti eccetto uno) o dal Senato alla Camera (si tratta di 13 senatori uscenti, tutti rieletti). In questo caso, come nel caso dei senatori uscenti che si presentano in un collegio diverso, fattori politici di altra natura fanno aggio sulla (possibile) influenza della territorializ- 
zazione. Se questo è il quadro a livello di schieramento, altre differenze sembrano emergere a livello partitico. Tali differenze tagliano trasversalmente le alleanze, discriminando fra partiti istituzionalizzati ( $\mathrm{Pds}$ e $\mathrm{An}$ ) e formazioni a minor grado di strutturazione (Forza Italia e le formazioni centriste). Mentre per queste ultime, dato il debole nesso tra incumbency e collegio che si registra nel passaggio 1994-1996, il maggioritario non sembra aver prodotto, almeno finora, l'attesa territorializzazione, per i primi non è possibile affermare altrettanto. Resta peraltro da accertare, in tal caso, se l'incumbency di collegio descriva effettivamente un fenomeno di territorializzazione (e quindi vada ascritto al legame tra il parlamentare e il suo collegio) oppure non rifletta, piuttosto, scelte e strategie adottate, a livello centrale, dal partito o dalla coalizione.

Nel passaggio 1994-1996 anche la gestione dell'arena proporzionale da parte di coalizioni e partiti presenta molteplici novità. La principale di esse, cui si è già fatto cenno, è la comparsa dei cartelli proporzionali. La loro origine ha motivazioni distinte. Ai cartelli in senso stretto, costituiti, come nel caso di Ccd-Cdu e di Rinnovamento Italiano-Lista Dini, dalla confluen$\mathrm{za}$ in liste comuni di formazioni altrimenti destinate a restare tagliate fuori in virtù della soglia del $4 \%$, si aggiungono aggregazioni che, come nel caso del Pds-Sinistra europea e delle liste Pop.-Svp-Pri-Ud-Prodi, rispondono principalmente a più generali esigenze di conduzione dell'alleanza elettorale. La comparsa di tali cartelli rafforza, in tal senso, l'interdipendenza fra maggioritario e proporzionale, in quanto utilizza l'arena proporzionale come stanza di compensazione dei rapporti e degli equilibri infracoalizionali definiti nei collegi uninominali. La tabella 16 presenta la composizione dei cartelli proporzionali nelle singole circoscrizioni. Nel caso dei cartelli in senso stretto se ne ricava un fenomeno di «proporzionalizzazione della proporzionale» che si realizza non tanto attraverso una ripartizione dei posti disponibili commisurata alla consistenza delle singole componenti del cartello in questione, ma, soprattutto, in un'attenta suddivisione delle posizioni di capolista - decisive in un sistema proporzionale a liste bloccate - e nell'applicazione di un criterio ordinale che assicura alla componente di appartenenza del capolista - soprattutto nei casi in cui il capolista guidi il cartello anche in altre circoscrizioni o sia candidato anche in un collegio uninominale - la titolarità della seconda posizione. La proporzionalizzazione della proporzionale non esclude, come si è det- 


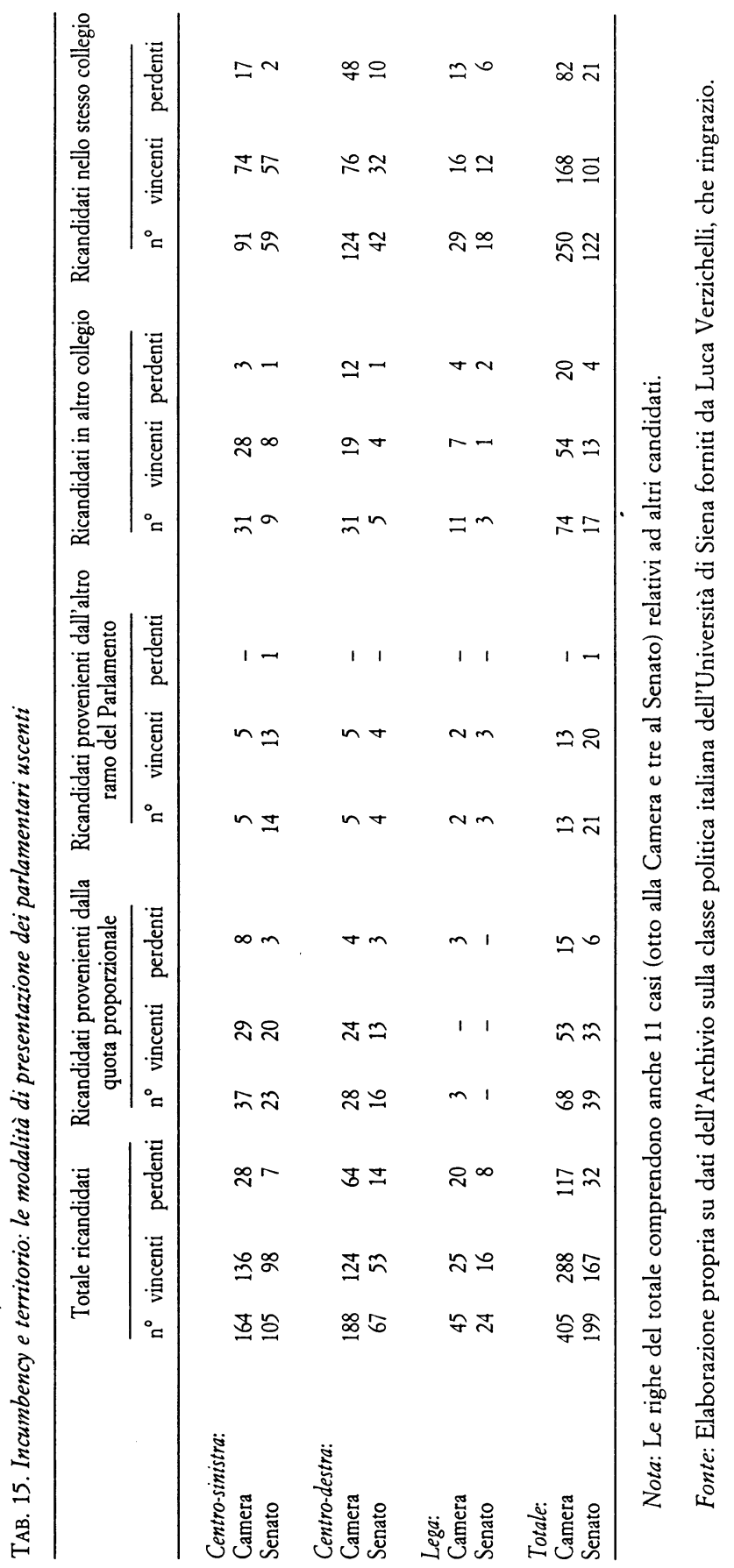


to, l'impiego di criteri compensativi. Il Pds, ad esempio, utilizza l'arena proporzionale per garantire un seggio sicuro ai cristianosociali, penalizzati dalla ripartizione dei collegi uninominali, e per «sistemare» due parlamentari comunisti unitari (Marida Bolognesi e Angelo Altea) il cui collegio di provenienza era stato reclamato in modo ultimativo da Rifondazione comunista. In maniera analoga, il Ppi accorda agli alleati alcune posizioni di capolista, per compensare il limitato spazio loro accordato nei collegi - e per assicurare, non sempre con successo, una posizione comoda e visibile ad alcuni laici di prestigio (Prodi, Maccanico, La Malfa, Zanone); questo stesso motivo è all'origine del maggior spazio concesso ai socialisti italiani rispetto al Patto Segni nelle liste di Rinnovamento italiano.

Una seconda novità nella gestione dell'arena proporzionale ha investito le strategie di collegamento tra i candidati dei collegi uninominali della Camera e le liste proporzionali. Mentre nel 1994 le singole coalizioni seguirono, in proposito, criteri differenziati e molteplici ${ }^{58}$, in questa occasione si registra un generalizzato ricorso al collegamento secco (di ciascun candidato con una sola lista proporzionale), adottato dal centro-destra nella totalità dei collegi e dal centro-sinistra nel $93 \%$ di essi. Quando si configura come «collegamento alternato» - secondo un modo di procedere che attribuisce l'onere del collegamento in base al criterio dell'appartenenza del candidato -, tale scelta razionalizza i costi dello scorporo, ripartendoli, appunto, secondo il criterio dell'appartenenza dei candidati vincenti. Il collegamento secco, tuttavia, può seguire anche un diverso criterio, celando accordi compensativi e spartitori oppure configurandosi come ricorso camuffato alla strategia della «lista fittizia». Nello schie-

58 Due anni fa, la strategia prevalente fu quella del «collegamento completo», ovvero del collegamento del candidato comune di collegio con tutte le liste partitiche che lo sostenevano. Il collegamento completo venne adottato in poco più del $40 \%$ dei casi (e, più specificamente, in oltre l' $80 \%$ dei casi dal Polo delle libertà e dal Polo del buongoverno e nel $40 \%$ dei casi dal cartello dei Progressisti). Ad esso si accompagnava la strategia del «collegamento alternato», prevalente nel polo di centro, secondo la quale ciascuna lista si fa carico del collegamento solo per i candidati che riconosce come propri. In un numero più contenuto di collegi, infine, si erano adottati altri modi di procedere: il «collegamento incompleto», una variante della strategia del collegamento completo, nel $20 \%$ dei collegi; il «collegamento alternato per esplicita rinuncia», nel $10 \%$ dei collegi; la strategia della «lista fittizia», con cui le liste dell'aggregazione rinunciano al collegamento per poter aggirare i costi dello scorporo, in 18 collegi. Traggo i dati e le indicazioni da D'Alimonte e Chiaramonte $(1995,51-66)$ che seguo anche con riferimento agli altri aspetti della competizione proporzionale. 


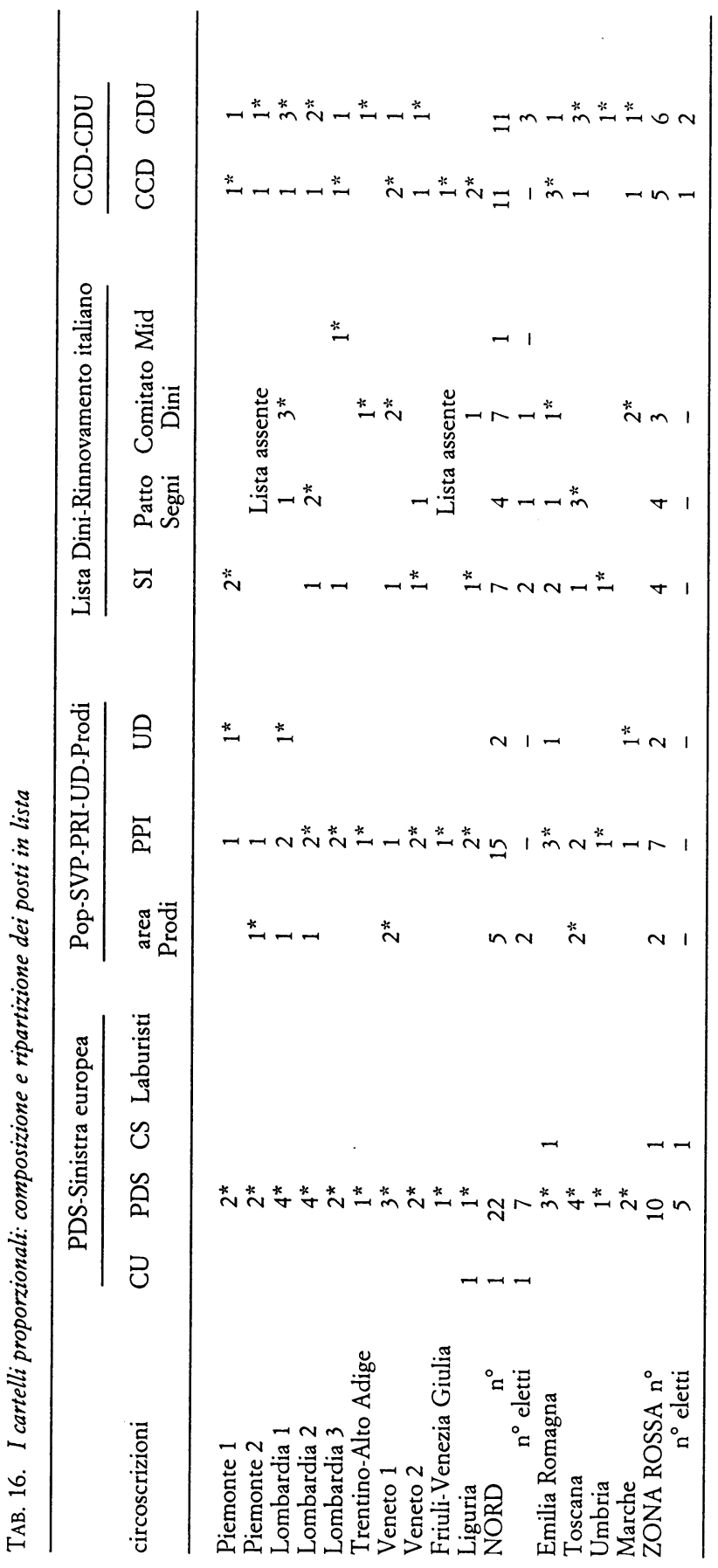




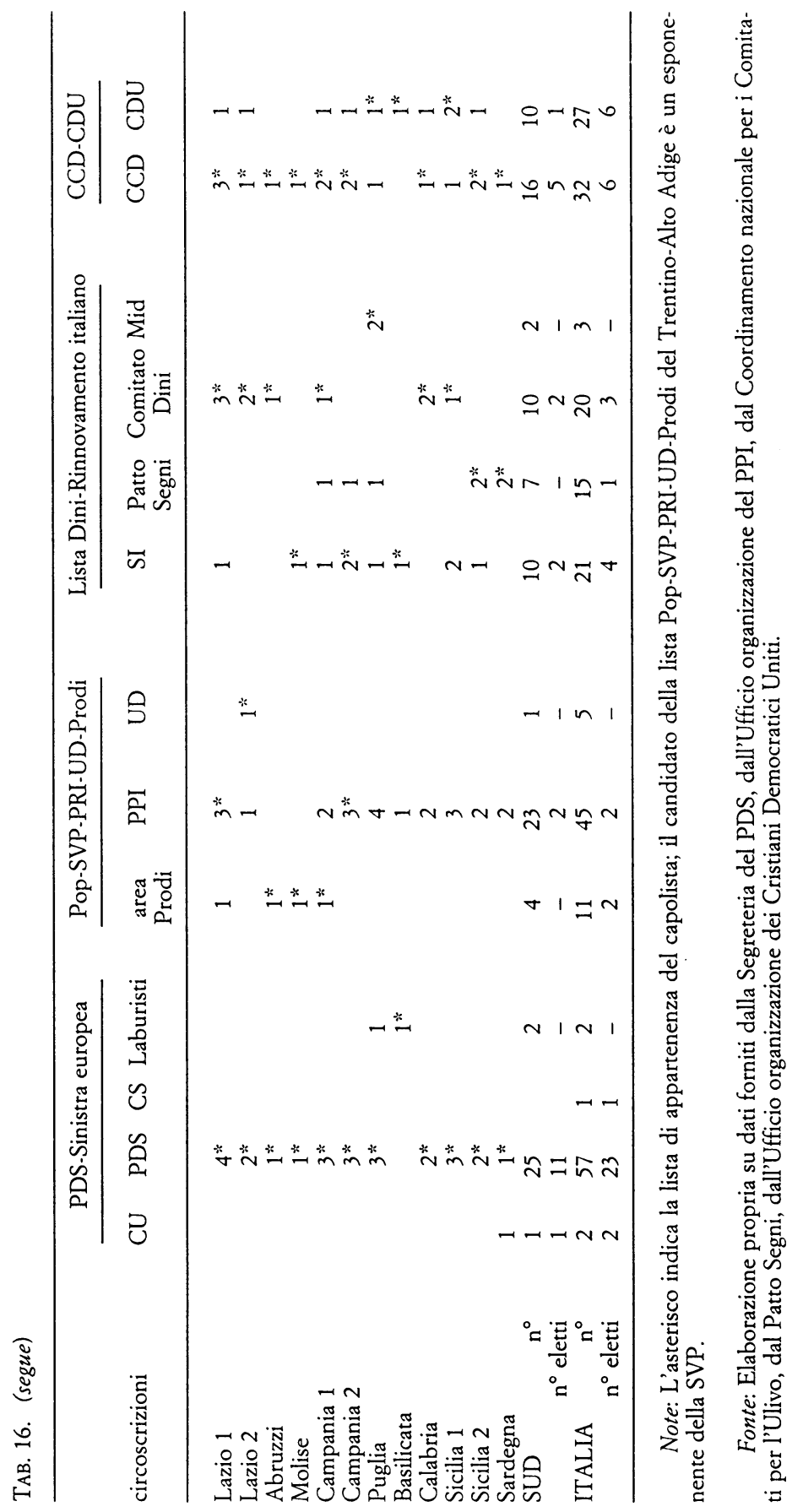


ramento di centro-sinistra, la prima ipotesi si realizza, ad esempio, in quei collegi in cui il candidato dello schieramento di area Pds o di area Prodi si trova collegato - a seguito di una scelta strategica negoziata al tavolo dell'Ulivo ${ }^{59}$ - con la lista dei Verdi (come, ad esempio, nel caso di Federico Orlando, con una scelta che consente al Pds di conseguire nel Molise un seggio proporzionale); la seconda possibilità trova invece corso in Sardegna, con otto collegamenti «fittizi» dei candidati dell'Ulivo con la lista del Partito Sardo d'Azione. In 24 collegi, infine, il centro-sinistra fa ricorso a collegamenti plurimi ma incompleti: in Umbria, dove i candidati della coalizione sono collegati al Pds-Se, alla Lista Dini e ai Verdi; nelle Marche, dove sono collegati al Pds-Se, ai Popolari per Prodi e ai Verdi, con una scelta che consente al Pds di ottenere un seggio proporzionale e di sottrarlo a Rifondazione; nella maggior parte dei collegi assegnati ai candidati progressisti, per i quali Rc ottiene al tavolo della desistenza un collegamento plurimo (con Pds-Se, Popolari per Prodi e Verdi), in modo da alleggerire l'onere dell'eventuale scorporo con una ripartizione pro quota.

A differenza di quanto era accaduto nel 1994 , i partiti nazionali tendono a presentare liste in tutte le circoscrizioni e a presentare liste complete (si vedano le tabb. 17 e 18). Il numero dei candidati presenti nell'arena proporzionale è così in crescita; la quota di candidati proporzionali presenti anche nei collegi, già modesta nel 1994, appare invece in leggero calo (i candidati presenti in entrambe le sedi rappresentano il $27,2 \%$ del totale, contro il 29,8\% nel 1994). Nel caso del Pds e di Forza Italia, tuttavia, il loro numero è crescente, così come, in misura decisamente più elevata (23 candidati su 32 ), nel caso della Lega. Alleanza nazionale, al contrario, riduce il tasso di sovrapposizione tra candidati uninominali e candidati proporzionali (nel 1994 più del $70 \%$ di questi ultimi era presente, nel caso di An, anche in un collegio; nel 1994 la quota si riduce al 49\%).

59 Al tavolo dell'Ulivo si era discusso anche di un impiego su ampia scala della tecnica della «lista fittizia», utilizzando a ciò le liste dei Verdi, alle quali il traguardo del $4 \%$ sembrava precluso in partenza. Ad un'opzione generalizzata di questo tipo, che avrebbe potuto essere stigmatizzata dalla coalizione avversaria, si è poi preferito il ricorso a una scelta mirata, circoscritta a quei collegi in cui il collegamento secco secondo criteri di convenienza anziché di appartenenza poteva essere effettivamente decisivo. La compensazione a favore dei Verdi è avvenuta, come si è visto nella tabella 13, sul piano della ripartizione qualitativa dei collegi uninominali. 
TAB. 17. I candidati proporzionali

\begin{tabular}{|c|c|c|c|c|c|}
\hline \multirow[b]{2}{*}{ Liste } & \multirow{2}{*}{$\frac{\text { Tot. candidati }}{n^{\circ}}$} & \multicolumn{2}{|c|}{ Candidati Proporzionale } & \multicolumn{2}{|c|}{ Candidati $\mathrm{Pr} / \mathrm{Mg}$} \\
\hline & & $n^{\circ}$ & $\%$ & $\mathrm{n}^{\circ}$ & $\%$ \\
\hline PDS-SE & 63 & 36 & 57,1 & 27 & 42,9 \\
\hline $\mathrm{RC}$ & 63 & 56 & 88,9 & 7 & 11,1 \\
\hline Verdi & 63 & 55 & 87,3 & 8 & 12,7 \\
\hline Pop-SVP-PRI-UD-Prodi & 61 & 47 & 77,0 & 14 & 23,0 \\
\hline Lista Dini & 59 & 50 & 84,7 & 9 & 15,3 \\
\hline Lega nord & 32 & 9 & 28,1 & 23 & 71,9 \\
\hline Pannella-Sgarbi & 47 & 44 & 93,6 & 3 & 6,4 \\
\hline CCD-CDU & 59 & 47 & 79,7 & 12 & 20,3 \\
\hline Forza Italia & 63 & 42 & 66,7 & 21 & 33,3 \\
\hline AN & 63 & 32 & 50,8 & 31 & 49,2 \\
\hline MS-Tricolore & 48 & 34 & 70,8 & 14 & 29,2 \\
\hline Totale & 620 & 452 & 72,8 & 169 & 27,2 \\
\hline
\end{tabular}

Il destino dei candidati proporzionali, di quelli che si presentano soltanto nella liste come di coloro presenti anche nel collegio, è spesso determinato dalla struttura delle liste. Anche a questo riguardo, il confronto 1994-1996 lascia emergere una normalizzazione dei comportamenti degli attori. Il ricorso alla tecnica della «lista corta» diventa sporadico, mentre non hanno corso strategie incentrate su uno svuotamento intenzionale delle liste (nei casi in cui la lista si svuota, ciò sembra infatti dovuto più all'esito non previsto della competizione maggioritaria che a una scelta definita ex ante) (tab. 18) ${ }^{60}$. Anche questa volta, tuttavia, non sono mancati i casi di candidati uninominali sconfitti nel collegio ed eletti grazie alla proporzionale. Il repêchage interessa i 17 candidati (nel 1994 erano 15) riportati nella tabella 19. Nel caso dei quattro candidati leghisti si tratta di una scelta implicita nell'ampia area di sovrapposizione tra candidati uninominali e candidati proporzionali; per il resto, il recupero è frutto per lo più dell'opzione di candidati eletti in più circoscrizioni proporzionali ed eventualmente anche in un collegio (è il caso di alcuni leader partitici quali Berlusconi, Bossi, Buttiglione). Il risultato proporzionale di An nel Lazio 1 segnala, infine,

$60 \mathrm{Nel}$ 1994, An aveva presentato in dodici circoscrizioni «liste corte», inserendovi per lo più, come si è detto, candidati di collegio, ed era giunta a collezionare ben otto «liste vuote» - liste cioè nelle quali tutti $\mathrm{i}$ candidati risultano eletti nei collegi - con conseguente repêchage di candidati uninominali sconfitti negli scontri di collegio. 


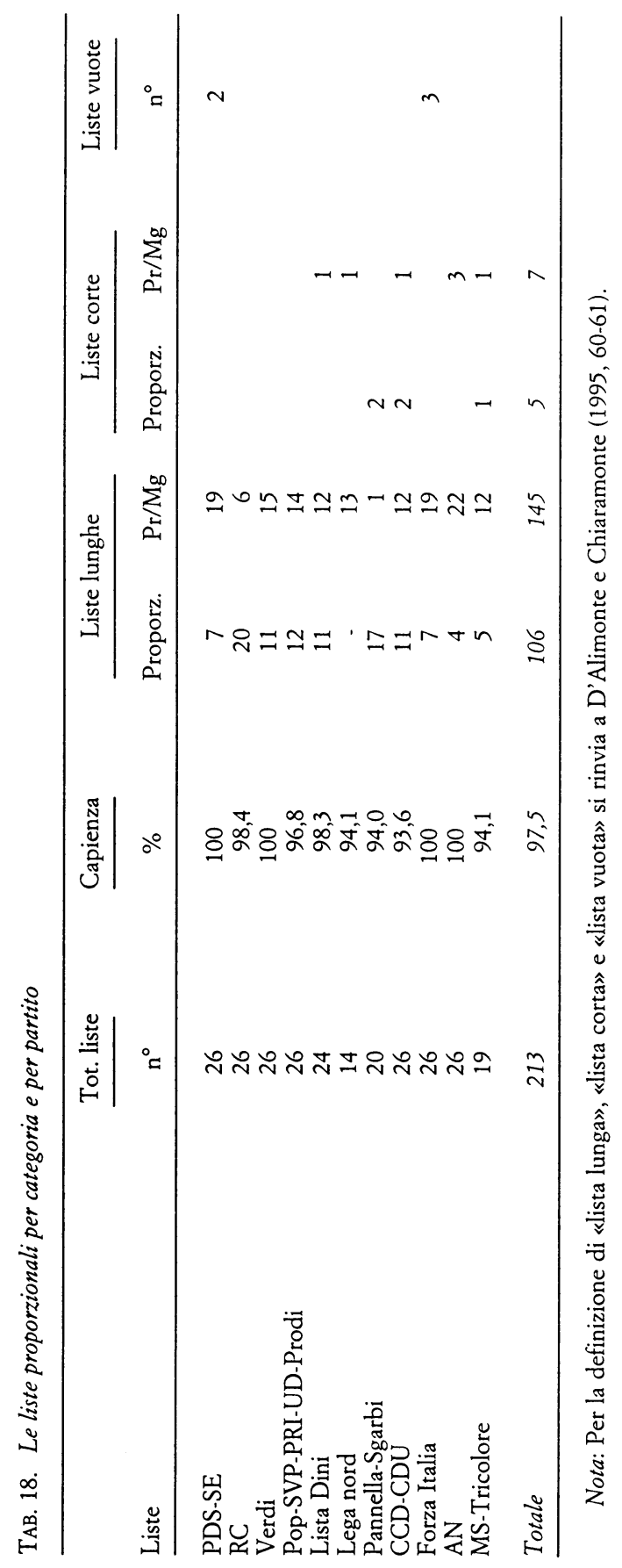


TAB. 19. Candidati uninominali eletti grazie alla proporzionale

\begin{tabular}{|c|c|c|c|c|}
\hline Candidato uninominale & Circoscrizione & Liste collegate & $\begin{array}{l}\text { Appartenenza } \\
\text { effettiva }\end{array}$ & $\begin{array}{l}\text { Lista per la quale } \\
\text { è stato eletto }\end{array}$ \\
\hline Cavaliere & Veneto 2 & Lega nord & Lega nord & Lega nord \\
\hline Chincarini & Veneto 1 & Lega nord & Lega nord & Lega nord \\
\hline Gambato & Veneto 2 & Lega nord & Lega nord & Lega nord \\
\hline Fontanini & Friuli-Venezia Giulia & Lega nord & Lega nord & Lega nord \\
\hline Cesaro & Campania 1 & Forza Italia & Forza Italia & Forza Italia \\
\hline Colombini & Piemonte 1 & Forza Italia & Forza Italia & Forza Italia \\
\hline Del Barone & Campania 1 & Forza Italia & Forza Italia & Forza Italia \\
\hline Garra & Sicilia 2 & Forza Italia & Forza Italia & Forza Italia \\
\hline Guidi & Puglia & Forza Italia & Forza Italia & Forza Italia \\
\hline Leone & Puglia & Forza Italia & Forza Italia & Forza Italia \\
\hline Sgarbi & Friuli -Venezia Giulia & Forza Italia & Forza Italia & Forza Italia \\
\hline Stradella & Piemonte 2 & Forza Italia & Forza Italia & Forza Italia \\
\hline Gramazio & Lazio 1 & AN & AN & AN \\
\hline Napoli & Calabria & AN & AN & AN \\
\hline Proietti & Lazio 1 & AN & AN & AN \\
\hline Ostilio & Puglia & CCD-CDU & CCD & CCD-CDU \\
\hline Di Bisceglie & Friuli-Venezia Giulia & PDS & PDS & PDS \\
\hline
\end{tabular}

un caso di ripescaggio «coatto»: in virtù del crollo di Forza Italia e del mediocre risultato del Polo nei collegi uninominali, la lista di An «scorpora» poco e, per il punteggio riportato, si vede assegnati cinque seggi, uno in più del numero massimo di candidati presentabili nella lista.

\section{La dimensione dell'apprendimento}

Che cosa emerge dall'accostamento degli attori (partiti e coalizioni) alle nuove regole elettorali dopo la seconda applicazione del meccanismo di voto adottato nell'estate 1993? E cosa si ricava, a questo proposito, dal confronto 1994-1996?

Una prima rilevante evidenza empirica è il confermato protagonismo dei meccanismi di proporzionalizzazione delle alleanze. Corroborati dalla disponibilità di affidabili «quotazioni» dei singoli attori-partito alla borsa valori del proporzionale e dal potere di ricatto che il sostanziale equilibrio nei rapporti di forza fra le due coalizioni accorda anche ai partner minori, i criteri spartitori, già presenti nel 1994, appaiono, nel 1996, una routine ormai consolidata. Investono non più soltanto la ripartizione dei collegi uninominali e quindi la competizione maggioritaria, ma anche, come si è visto, l'arena proporzionale e le strategie di 
collegamento tra candidati uninominali e liste per la Camera; impegnano una parte non piccola delle risorse destinate dagli attori all'innovazione strategica (è il caso, essenzialmente, della ridefinizione della composizione e dei criteri di conduzione dell'alleanza che caratterizza il centro-sinistra e che si fonda, in buona parte, proprio sul «perfezionamento» dei meccanismi negoziali e di distribuzione compensativa delle spoglie fra i partner della coalizione); guadagnano facilmente lo schieramento di centro-destra, che due anni or sono aveva evitato le trappole della proporzionalizzazione (in particolare, la trappola dell'autoreferenzialità della coalizione in cui era invece caduta l'alleanza progressista) verticalizzando l'accordo e riuscendo a far prevalere l'obiettivo della costruzione della coalizione rispetto all'interesse delle sue singole componenti.

Quest'ultimo elemento pone all'attenzione una seconda, decisiva, indicazione emersa dall'analisi condotta fin qui: la costruzione della coalizione si impone, nel 1996 come nel 1994, come fattore cruciale della competizione maggioritaria e, in definitiva, dello stesso risultato elettorale. L'offerta coalizionale più consona all'operatività del sistema elettorale viene, anche in questa seconda occasione, premiata dal voto: non si tratta di una mera (e circolare) constatazione ex post factum, bensì dell'evidenza che a scelte tattiche e politiche aderenti alla struttura degli incentivi inscritti nella nuova legge elettorale corrisponde, nel 1996 come nel 1994, un valore aggiunto coalizionale che fa la differenza e che si manifesta, ad esempio, in un sistematico surplus di consenso ai candidati uninominali dello schieramento vincente rispetto alla somma dei voti accordati alle rispettive liste proporzionali ${ }^{61}$.

Nel 1994 l'«effetto coalizione» aveva favorito lo schieramento di centro-destra, che aveva colto al volo le implicazioni del nuovo sistema elettorale e ne aveva meglio sfruttato le caratteristiche; nel 1996, come è emerso dall'esame della composizione e delle modalità di regolazione delle due aggregazioni elettorali, a trarne vantaggio è invece il centro-sinistra. Nel primo caso, il tempismo politico di Berlusconi e la sua estraneità al vecchio mondo politico - applicati a due intuizioni strategiche determinanti: l'apertura a destra e la differenziazione territoriale delle alleanze (Di Virgilio 1995) - erano stati sufficienti allo scopo.

61 Il fenomeno è esaminato da Bartolini e D'Alimonte (1995b) e da D'Alimonte e Bartolini (1996). 
Nel caso del centro-sinistra, la costruzione di una coalizione capace, se se ne fosse presentata l'occasione, di vincere le elezioni è stata invece il risultato di un processo meno estemporaneo, in cui slanci innovativi e meccanismi di apprendimento si saldano tra loro. La bruciante sconfitta del 1994, del resto, induceva di per sé al cambiamento e alla ricerca di nuove procedure coalizionali. Non deve sorprendere, quindi, che la costruzione dell'alleanza di centro-sinistra, come si è visto, sia avvenuta quasi per contrapposizione rispetto al cartello progressista: dal paralizzante assemblearismo dei molteplici tavoli coalizionali alla centralizzazione e allo snellimento delle procedure decisionali ${ }^{62}$; dai risentiti veti di Leoluca Orlando nei confronti degli esponenti repubblicani e socialisti a un'articolazione che irrobustisce visibilmente il fianco destro dell'alleanza; da una tattica coalizionale rigida e assai poco consapevole dei vincoli e delle opportunità del maggioritario a scelte tattiche quasi disinvolte (l'accordo di desistenza tra l'Ulivo e Rifondazione, l'arruolamento di Dini, l'estensione politico-ideologica che ne deriva) che vanno di pari passo alla focalizzazione dell'attenzione strategica sui collegi marginali.

Questo passaggio ha avuto nel Pds - ed è questa la terza evidenza da rilevare - il suo principale protagonista. Il partito di D'Alema si adatta alla logica del maggioritario, assume il successo elettorale della coalizione come proprio obiettivo prioritario, investe strategicamente in tale direzione. Queste scelte, che impegnano il partito in prima persona ${ }^{63}$ e al tempo stesso mobilitano competenze esterne, consentono al Pds di forgiare la coalizione e di ottimizzare la gestione della campagna elettorale. L'osservatorio sui collegi uninominali e il monitoraggio dei col-

62 Ciò avveniva, paradossalmente, mentre da parte di alcune componenti dell'alleanza (da Alleanza democratica ai Verdi) e all'interno degli stessi Comitati Prodi ci si attardava sulla rivendicazione di elezioni primarie per la selezione dei candidati. Tale iniziativa intendeva non solo promuovere i c.d. candidati non-professionisti-della-politica, ma soprattutto contrastare il ruolo del Pds all'interno della coalizione, ignorando, peraltro, che le elezioni primarie, oltre a favorire le interferenze dei media e a privilegiare il ruolo dei pubblici intensi, non escludono la possibilità di manipolazioni partitiche (Sartori 1994, 29-30) e, nel caso specifico, avrebbero avvantaggiato proprio il Pds, consentendogli di far eleggere con estrema facilità i propri candidati.

63 L'imputazione su supporto magnetico dei risultati regionali su base comunale, che ha costituito la base di partenza su cui la Segreteria del Pds ha costruito e via via aggiornato le proprie analisi sulla dinamica del profilo politico dei collegi uninominali, ha ad esempio impegnato per settimane, a ridosso del voto regionale, lo staff tecnico del partito. 
legi marginali cui si è fatto riferimento, ad esempio, costituiscono per il partito risorse aggiuntive significative, spendibili nei rapporti infracoalizionali e utili per accrescere la Koalitionsfäbigkeit dello schieramento. Facendo asse, su questo punto, con un Ppi munito anch'esso di autonome risorse in termini di professionalità politica, presenza territoriale e capacità di gestione, il Pds utilizza tali mezzi come strumento di conduzione della coalizione, nonché, come si è avuto modo di vedere, di salvaguardia delle sue stesse posizioni. Tali innovazioni, inoltre, rendono più efficace e selettiva la campagna elettorale, attraverso una politica dei collegi marginali che punta a convogliare sforzi e risorse laddove è più necessario. Il tentativo è ancora embrionale, viene accolto senza entusiasmo dagli alleati e va incontro a resistenze interne. La direzione di marcia, tuttavia, appare evidente e contempla, ad esempio, la selezione di candidati ad boc - «tagliati» sulla base delle misure socio-territoriali del collegio marginale in questione ${ }^{64}$ oppure, se esterni al collegio, altrimenti dotati di appeal personale -, una localizzazione nei collegi marginali degli interventi dei leader più noti, la definizione di specifici schemi d'azione per lo svolgimento della campagna in tali collegi, la focalizzazione in tali aree della propaganda elettorale ${ }^{65}$.

Se gli attori sconfitti del 1994, e il Pds in particolar modo, imparano la lezione e si attrezzano di conseguenza, lo schieramento allora vincente - lo si è visto nelle sezioni precedenti ed è questa una quarta e ultima evidenza - appare incapace di innovazione ed esposto, anzi, a una spirale di disapprendimento che ne rende formato e strategia inadeguati, da più punti di vista, all'operatività del sistema elettorale. Lo schieramento subisce, per un verso, le negative conseguenze della sua stessa frammentazione; per altro verso, proprio nel momento in cui il divorzio dalla Lega e il dissolvimento del Polo delle libertà impedivano di reiterare l'efficace formula di due anni prima, perde in capacità coalizionale. Tali fenomeni indicano, retrospettivamente, quanto il successo del 1994 dipendesse dall'abilità imprenditoriale di Berlusconi e quanto poco, invece, dalla consapevolezza istituzionale degli attori. Se le disavventure politicogiudiziarie dello stesso Berlusconi contribuiscono a minare la coesione della coalizione e spiegano, almeno in parte, lo scarso

64 Si veda la nota 43.

65 Traggo queste informazioni dai colloqui avuti con Gianni Cùperlo e Mauro Zani. 
gioco di squadra che caratterizza il comportamento delle singole componenti dell'alleanza, colpisce, tuttavia, la povertà di competenze e di strumenti tecnici che il centro-destra sembra aver messo in campo, a quanto risulta, per bilanciare l'apprendimento della coalizione avversaria ${ }^{66}$. Anche a questa sfida, che per il centro-destra si presenta come decisiva già nel breve termine, sembra legato il principale limite della coalizione: l'incapacità di tradurre in seggi maggioritari un seguito elettorale che nell'arena proporzionale resta ancora soverchiante.

Confezionare un'offerta coalizionale adeguata si è dunque confermato, in questa seconda prova maggioritaria, un elemento decisivo della contesa. In che misura le innovazioni e l'apprendimento del centro-sinistra abbiano pesato, se hanno pesato, sul risultato del voto e quanto invece vi abbia influito l'inadeguatezza coalizionale e il disapprendimento del centro-destra non è facile da stabilire ${ }^{67}$. Da quanto si è visto, tuttavia, si può affermare che il centro-sinistra si presentava al voto coalizionalmente ben attrezzato e in grado quindi di non farsi cogliere impreparato dal prodursi - più a causa delle defaillances del Polo che per «meriti» propri - di condizioni competitive assai favorevoli.

\section{Riferimenti bibliografici}

Bartolini, S. e R. D'Alimonte (a cura di) (1995a), Maggioritario ma non troppo. Le elezioni politiche del 1994, Bologna, Il Mulino.

- (1995b), La competizione maggioritaria: le origini elettorali del parlamento diviso, in Bartolini e D'Alimonte (1995a), pp. 317-372.

Caciagli, M. e D.I. Kertzer (a cura di) (1996), Politica in Italia. I fatti dell'anno e le interpretazioni. Edizione '96, Bologna, Il Mulino.

Calvi, G. e A. Vannucci (1995), L'elettore sconosciuto. Analisi socioculturale e segmentazione degli orientamenti politici nel 1994, Bologna, Il Mulino.

66 Dalle fonti citate nella nota 49, ad esempio, non risulta che il Polo abbia messo a punto una qualche politica dei collegi marginali. Il rendimento ottenuto nei collegi ritenuti sicuri e nei collegi ritenuti marginali dalla coalizione (riportato nella tabelle 9, 11 e 12) sembra del resto attestare non soltanto una scarsa capacità previsionale, ma soprattutto un'insufficiente «consapevolezza territoriale» che fa capo probabilmente a un difetto di insediamento.

67 Argomentando, con riferimento alla prova del centro-destra, di «maggioranza dissipata», D’Alimonte e Bartolini (1996) propendono per la seconda ipotesi, attribuendo l'esito del voto maggioritario più alla sconfitta del centro-destra che al successo del centro-sinistra. 
D'Alimonte, R. (1995), La transizione italiana: il voto regionale del 23 aprile, in «Rivista Italiana di Scienza Politica», 3, pp. 515-558.

D'Alimonte, R. e S. Bartolini (1996), Come perdere una maggioranza. La competizione nei collegi uninominali, in «Rivista italiana di scienza politica», questo numero.

D'Alimonte, R. e A. Chiaramonte (1995), Il nuovo sistema elettorale italiano: le opportunità e le scelte, in Bartolini e D'Alimonte (a cura di), pp. 37-81.

Di Virgilio, A. (1995), Dai partiti ai poli, in Bartolini e D'Alimonte (a cura di), pp. 177-232.

- (1996), Le elezioni regionali e amministrative: bipolarizzazione con riserva, in Caciagli e Kertzer, pp. 57-86.

Katz, R. (1996), Electoral Reform and theTransformation of Party Politics in Italy, in «Party Politics», 1, pp. 31-53.

Gilbert, M. (1996), L'Ulivo e la Quercia, in Caciagli e Kertzer, pp. 121-138.

Ignazi, P. (1995), Il peso del Pds sul centro-sinistra, in XLIV, 359, maggio-giugno, pp. 458-465.

Maraffi, M. (1996), Forza Italia dal governo all'opposizione, in Caciagli e Kertzer, pp. 139-157.

Mattina, L. e A. Tonarelli, I candidati. Visioni politiche e carriere, in «Rivista italiana di scienza politica», questo numero.

Panebianco, A. (1996a), Dini e la sfida dei mutanti, in «Corriere della sera», 26 febbraio.

- (1996b), Doppio errore per il Polo, in «Corriere della sera», 3 maggio.

Sartori, G. (1994), Ingegneria costituzionale comparata. Strutture, incentivi ed esiti, Bologna, Il Mulino.

- (1996), Esistere e desistere, in «Corriere della sera», 21 febbraio.

Verzichelli, L. (1996a), I gruppi parlamentari dopo il 1994. Fluidità e riaggregazioni, in «Rivista Italiana di Scienza Politica», 2, pp. 341 413.

- (1996b), La classe politica della transizione, in «Rivista Italiana di Scienza Politica», questo numero. 